\title{
Exploring the entanglement of personal epistemologies and emotions in students' thinking
}

\author{
Ayush Gupta, ${ }^{1}$ Andrew Elby, ${ }^{1,2}$ and Brian A. Danielak ${ }^{3}$ \\ ${ }^{1}$ Department of Physics, University of Maryland, College Park, Maryland 20742, USA \\ ${ }^{2}$ Department of Teaching and Learning, Policy and Leadership, University of Maryland, \\ College Park, Maryland 20742, USA \\ ${ }^{3}$ Reaktor Inc., New York, New York 10010, USA
}

(Received 5 October 2016; revised manuscript received 13 July 2017; published 25 May 2018)

\begin{abstract}
Evidence from psychology, cognitive science, and neuroscience suggests that cognition and emotions are coupled. Education researchers have also documented correlations between emotions (such as joy, anxiety, fear, curiosity, boredom) and academic performance. Nonetheless, most research on students' reasoning and conceptual change within the learning sciences and physics and science education research has not attended to the role of learners' emotions in describing or modeling the fine timescale dynamics of their conceptual reasoning. The few studies that integrate emotions into models of learners' cognition have mostly done so at a coarse grain size. In this study, toward the long-term goal of incorporating emotions into models of in-themoment cognitive dynamics, we present a case study of Judy, an undergraduate electrical engineering and physics major. We show that shifts in the intensity of a fine-grained aspect of Judy's emotions, her annoyance at conceptual homework problems, co-occur with shifts in her epistemological stance toward differentiating knowledge about and the practical utility of real circuits and idealized circuit models. We then argue for the plausibility of a cognitive model in which Judy's emotions and epistemological stances mutually affect each other. We end with discussions on how models of learners' cognition that incorporate their emotions are generative for instructional purposes and research on learning.
\end{abstract}

DOI: 10.1103/PhysRevPhysEducRes.14.010129

\section{INTRODUCTION}

\section{A. Research on conceptual and epistemological reasoning does not attend to the role of emotions}

As instructors, educators, and education researchers, intuitively we know that students' emotions can influence their behaviors in science learning environments. Supporting these intuitions, cognitive scientists make a persuasive case that emotions, such as anger, joy, fear, disgust, or surprise, play a role in regulating performance on cognitive tasks [1-7]. Nonetheless, incorporating emotion into theories of science learning, though recognized as important, has proved to be a challenge [8-11].

For instance, despite a prominent assertion that emotions play a role in deep conceptual change [12], cognitivist accounts of student reasoning and conceptual change in science have primarily focused on the form and content of novices' knowledge but not on learners' emotions [13-18]. Research specifically on physics learning has also focused mostly on the form and content of students' ideas [19-25]. Indeed, two resource papers on physics education research

Published by the American Physical Society under the terms of the Creative Commons Attribution 4.0 International license. Further distribution of this work must maintain attribution to the author(s) and the published article's title, journal citation, and DOI. compile lists of research on students' ideas in content areas such as mechanics or thermodynamics, or on practices such as problem solving [26,27]; but research on physics learners' emotions did not receive its own category, nor do the papers in other categories foreground connections between affect or emotion and learning.

Similarly, research on students' "personal epistemologies" - their views about what counts as knowledge and knowing [28] - and how those views affect reasoning and learning has also largely ignored the role of emotions. In physics education research (PER), numerous papers explore relations between epistemological stances and conceptual reasoning and learning but leave out emotions [29-36]. However, as we review next, researchers are starting to build these connections between conceptions, epistemologies, and emotions.

\section{B. Learners conceptual and epistemological reasoning might be linked to their emotions}

Before launching our brief literature review, we wanted to define the construct of emotion. Understanding the boundaries of what constitutes emotions, categorizing and defining them, and deciding on their ontology is an ongoing debate [37,38]. Without reproducing these debates here, we would like readers to consider emotions to refer to phenomena such as joy, fear, anger, disgust, dissatisfaction, 
surprise, curiosity, etc. These phenomena are often locally produced in interaction, and are short lived in time, though they could recur over multiple events, and get associated with particular events, artifacts, or people, impacting memory and recall $[2,4,39]$. Emotions are often characterized in terms of two subjective states: valence and arousal [40]. Valence refers to the experience of pleasantness or unpleasantness, also called positive or negative valence, respectively. Arousal refers to bodily activation or deactivation. At times in the paper, instead of characterizing an emotional state in terms of a discrete emotion such as joy or fear, we might only refer to the valence of the emotional state. We conceptualize emotions as distinct from other affective phenomenon such as mood or interest that are longer lasting [8]. ${ }^{1}$ Towards the end of the paper, we briefly engage with the ontology of emotions in the discussion to reflect on where some lines of that debate intersect with our analysis. In this brief literature review, we focus on the research that aims to establish that learners' conceptual and epistemological development is tied to their emotions. So, we do not review research on affective constructs such as "interest," "motivation," and "self-concept," or research that focuses on learners' emotions without simultaneous attention to conceptions or epistemologies.

Several threads of research have started to build a preliminary understanding of how learners' emotions contribute to learning processes. The cognitive-affective model of conceptual change [43] allows for emotions such as anxiety, the feeling of threat, and so on, to play a role in conceptual change. Pekrun et al. [44] document that higher academic achievement is correlated positively with academic joy and excitement, and negatively with boredom. In a similar vein, curiosity correlates with greater learning gains $[45,46]$. These examples correlate emotions with learning disciplinary content.

Some research has attended to the intertwining of emotions and epistemological beliefs [8,47-54]. For example, Boaler and Greeno [47] found that in a traditional, authoritarian classroom environment, a student can develop perceptions of mathematics as uncreative. For some students, this clashes with their preference toward understanding ideas via exploring multiple interpretations-an epistemological mismatch that produces negative emotion toward the subject itself. Eynde, Corte, and Verschaffel [50] argue that learners' emotions during problem solving are intertwined with their interpretations and appraisals of the

\footnotetext{
${ }^{1}$ Affect has often been used as a catch-all term for a wide variety of phenomenon such as mood, emotions, feelings, values, beliefs, etc. (McLeod Adams). For a while, researchers have suggested that learning (and cognition) is affective. The notion of cognitive dissonance, for example, is acknowledged to have an affective dimension [12,41,42]. In a classic paper, Pintrich, Marx, and Boyle [9] argued for greater attention to "hot" cognition: models of cognition and learning that attend to the affective as well as the conceptual domains.
}

unfolding culturally situated activity, which are in turn intertwined with their epistemological and self-efficacy beliefs. Cobb, Yackel, and Wood [48] have argued that the formation of sociomathematical norms in the mathematics classroom, some of which incorporate epistemological norms about what counts as knowing and doing mathematics, are influenced by the teachers' and students' emotions.

Within physics education research, Bodin and Winberg [30] found that students' performance on a classical mechanics assignment correlated with expertlike beliefs and emotions (self-reported through a survey) associated with control and concentration. Alsop and Watts [55] suggest that students' attitudes towards learning topics such as radioactivity is influenced by their emotions towards the effects of radiation on living beings. They argue that our aim should be towards instruction that balances the learning of physics ideas with emotional wariness towards such topics, but they do not investigate how such balance might occur in an actual learning situation, or how the emotions they document become consequential when students are actually learning about the topic.

Before continuing, we note, in summary, that the empirical work linking emotions to conceptions and epistemologies does so at coarse grain size: emotions towards disciplines or courses or types of activity are linked to epistemological stances or conceptual learning in a given discipline, course, or activity.

\section{What is needed: Models that couple conceptions, epistemologies, and emotions at fine timescales}

Correlational studies $[30,44,45]$ are significant in furnishing empirical evidence that emotions influence learning, but they do not provide causal mechanisms through which the observed correlations arise.

Recent empirical evidence supports a view of novice knowledge as more dynamic, unstable, and contextual [31,33,35,56-60]. Researchers have argued for a similarly dynamic, contextual model of students' personal epistemologies [61] and emotions [37,50]. Given this view of knowledge, beliefs, and emotions as dynamic at short timescales of the order of seconds to minutes and the emerging evidence that the emotional and cognitive domains are interconnected $[2,3,5,54,62,63]$, it seems reasonable to ask what role do emotions play in generating stabilities and shifts in students' conceptual and epistemological reasoning?

\section{Our goal: Explore bringing emotions into analysis of in-the-moment cognition}

In this paper, we use a single "revelatory" case study [64] of "Judy" to argue for the feasibility and explanatory power of integrating conceptual, epistemological, and emotional elements at fine timescales (on the order of seconds to minutes). Judy was a physics and electrical engineering major taking a sophomore-level course on basic circuit 
theory. Our analysis shows that Judy, in some contexts but not others, argues that there is a wide gulf between real circuits and the idealized circuit models taught in the course, a gulf that renders qualitative or conceptual understanding of ideal circuits (idealized models) practically useless to her. We will argue that Judy's deep annoyance at the qualitative, conceptual homework problems, is coupled to this stance towards real circuits and idealized models. Specifically, we will first show how shifts in emotions cooccur with the shifts in the epistemological stances towards circuits. We argue that the explanation in which emotional and epistemological stances interact is at least as compelling as a "cold cognitive" explanation in which emotions are merely epiphenomenal (along for the ride).

Establishing the plausibility of the emotion-epistemology coupling, we argue for the need to consider seriously the implications of that model which differ significantly from a model of learning that does not include emotions. Specifically, if a learner's emotions play a significant role in sustaining their epistemological stance, as we argue is the case with Judy, then PER-style interventions targeting the learners' epistemologies or conceptions directly need not be the only instructional pathway. It might be effective, in some circumstances, to target the emotions sustaining an unfavorable epistemological stance. Additionally, emotion-epistemology coupling prompts us to reinterpret the results from attitudes and epistemology surveys in PER such as the Maryland Physics Expectations Survey (MPEX) [80] and the Colorado Learning Attitudes about Science Survey (CLASS) [79]. The model also has implications for course and classroom design. Creating fine timescale models of learning that integrate emotions, conceptions, and epistemologies creates a pathway for including other constructs such as identity in future. Finally, given the rapidly gaining consensus in neuroscience and cognitive psychology on the integration of emotions with other cognitive processes, emotion-inclusive models of learning provide a more global coherence to theories of learning. Thus, our argument for attending to learners' emotions rests on two supports: (i) a plausibility claim and (ii) pragmatic considerations that teases apart the emotion-inclusive and emotionexcluding models of learning.

\section{DATA COLLECTION AND METHODOLOGY}

\section{A. Interview population and procedures}

Our data corpus consists of videotaped clinical interviews of electrical engineering majors in a basic circuits course at a large public university. The homework and exams mixed "traditional" quantitative problems with conceptual questions asking students to interpret equations and/or explain physical processes (rather than plugging and chugging). These conceptual problems were cocreated by the course instructor and us. Sample course assignment questions are provided in Appendix A.

B. D. (third author) conducted one-hour semistructured interviews with Judy and with 3 other students to explore their approaches to and views or feelings about mathematics within the course. Appendix B includes a list of interview questions that Danielak had access to. In accordance with data collection procedures approved by the Internal Review Board for human subjects research, interviewees were paid 10 .

\section{B. Selection of the participant and the refined focus for this study}

Soon after each interview, Danielak viewed the videotape and generated a content log (brief summaries of the conversation and activities in each 3-5-minute segment). Given our research interest in students' approaches to and views or feelings toward math-related learning and problem solving within the course, Danielak specifically flagged segments of the video where the student (i) made explicit epistemological statements and, (ii) shared details on their experiences in the course, especially those involving the use of mathematics. By epistemological statements, we mean instances where students' utterances seemed to express their view towards knowing and learning in the context of the course, such as "I just think we need to memorize the circuits equations," or "I really try to understand what the equation is trying to say."

Then we and two other research group members (Kuo and Hull) watched the interview videotapes together as a group. Anyone was welcome to stop the tape if they wanted to talk about something [65-67]. Working as a group, we looked for patterns (repetitions or variability) in participants' responses, both within and across subjects.

At this stage Judy caught our attention because she talked about a deep divide between real world circuits and idealized models of these circuits and about being annoyed at the conceptual questions. Almost every time she talked about the conceptual questions or idealized circuits, we noticed Judy's annoyance in her tone, gestures, posture, and facial expressions. This was important to us because, if students were reacting negatively toward the conceptual questions, we would want to unpack and potentially resolve the issue in future offerings of the course. We thought that unpacking Judy's annoyance and understanding why and how she perceives a gulf between real and ideal circuits could help us think about instructional interventions. As a result, we started parsing Judy's interview more closely. A. G. independently content logged Judy's interview. Danielak and Gupta selected particular segments of the interview where initial viewings seemed to depict the phenomenon of interest. The next section describes the analytical commitments during the close parsing of Judy's data.

\section{Analytical commitments and flow}

There were two broad objectives in these repeated close viewings of data: to describe in detail what we are seeing in Judy's reasoning and behaviors, and to create models to explain that which we were describing. Since our interest 
was in describing patterns of behavior that hold together for seconds to minutes as well as changes in these behaviors, it required that our parsing of the video is at a similar timescale (or more frequent than the timescale of assumed change) [68]. So, our analysis (and our presentation of it in the paper) required a moment-by-moment analysis of unfolding reasoning within particular episodes. Our analysis, as presented here, is thicker for segments of the interview where we describe how different bits (conceptual, epistemological, emotional, etc.) are coming together to form a local coherence, or when we describe transitions. At other places, we summarize the interview segments. In this fine timescale modeling, we attended particularly closely to Judy's epistemological stances and emotions.

By epistemological stances we mean the orientation towards knowledge and learning adopted by someone in the moment and communicated through words or actions (Hammer and Elby [61]; Gupta and Elby [31]). To describe and model Judy's epistemological stances, we attended to the substance of Judy's utterances (such as when she says that the idealized models are not relevant for analyzing real circuits) and her actions during problem solving. Actions during problem solving helped us gauge the stance towards knowledge and learning that is tacitly adopted during problem solving.

To notice and interpret Judy's emotions we relied on tools that other researchers analyzing emotions have used $[49,50]$. We drew on emotion words stated by Judy (such as anger, annoyed, etc.) in utterances. Additionally, we drew on verbalized but nonsemantic utterances. For example, a long drawn-out "oooh" (accompanied with a smile) could indicate a pleasant surprise; an aspirated sigh (with a downward gaze, and a slight shaking of head) could be interpreted as rejection of something. As noted in these examples, we attended to co-occurring modalities-of gaze, gestures, posture, tone, and facial expressions [69] to strengthen our interpretations.

In our analysis, we did not a priori assume coherence in Judy's emotional or epistemological stances towards circuits; we continually considered how specific contextual cues might trigger different "local coherences" in her thinking $[16,32,35,70]$. Any coherence in Judy's stances towards circuits were empirically determined rather than assumed and required contextual explanation (rather than being a static property of her cognition).

In the tradition of fine-grained video analysis $[65,67]$ we created multiple competing interpretations when analyzing a particular segment. Then we revisited the data-either looking at the same segment through modalities we might have missed at first glance or looking at other segments to find triangulating evidence for or against one of the interpretations - in order to settle on an interpretation. Where we could not fully tease apart interpretations or where evidence for an interpretation is thin, we noted that in the analysis below. This analysis has gone through many cycles of such revision, the most recent after getting reviews on an earlier version of this manuscript. This final revision cycle led to further changes in our interpretation of the last segment of the data, with cascading minor changes in the interpretation of earlier segments. (A version of our earlier interpretation can be found in a conference proceedings paper [71].)

Each interpretive claim at a given moment in our analysis might have less "strength" than an airtight interpretation of that specific moment but these different claims add up to make the stronger plausibility claim for emotion-epistemology coupling as an explanation for observed patterns in Judy's behavior. We also try to mark which of our interpretations are more speculative, and in specific cases, we entertain multiple interpretations of a particular observation and if alternative interpretations support or refute the overall claim of emotionepistemology coupling. Since simultaneous attention to emotions and conceptual or epistemological reasoning is relatively underexplored in fine-grained video analysis, we present our analysis in great descriptive and interpretive detail in order to help the interested reader form their own opinion and evaluate our interpretations.

\section{Analytical omissions and limitations}

In the next section, we present the data and our analysis of the interview with Judy. We struggle with how much else we should say about Judy. We coded her as female based on presentation, which is why we are using the pronoun "her," but we did not ask her to report gender on a demographic form or talk about her gender in relationship to her course experience. We know little about her ethnic background except that she would be coded as Asian based on presentation. We have little information about other aspects of her that might affect how she experiences the course and the engineering program, such as socioeconomic background, nationality, sexuality, social life, networks of friends or study groups, etc. This is important because, in the story we build, we argue that her knowledge and epistemological stances towards circuits are entangled with her emotions as shaped by her lived experience in the course. And it is likely that her lived experience is dimensioned by race, gender, class, schooling history, campus climate, sexuality, and many other factors. We are limited in that we did not design our interview to get at the lived experience or at emotions; we stumbled upon these issues when exploring the issue of epistemology. As a responsive interviewer, Brian pursued relevant emergent themes such as Judy's double major status and her emotional reactions to the course. They have subsequently become central in our analysis.

By contrast, many other aspects, including race, gender, sexuality, nationality, financial status, friendships, could be important but did not get a chance to emerge within the interview. Our inability to speak to these aspects of Judy's lived experience, despite their potential influence on the 
emotion-epistemology coupling we document, is more than just a limitation of our analysis; it contributes to the silencing of these other aspects of students' lived experiences within the broader endeavor of education research. However, we see some value in focusing on and fleshing out the particular emotion-epistemology coupling we are documenting. It is in light of these limitations that the analysis below should be read and interpreted.

\section{DATA AND FINDINGS}

In this section, we chronologically present episodes from the interview with Judy. We interweave our interpretations and reflections with transcript snippets. We use the present tense in our descriptions, with a view of taking the reader on this interpretive journey with us as they see the data unfold. For ease of following the argument, we break the interview into three "episodes" of data. The first, corresponding to the first $15 \mathrm{~min}$ of the interview, illustrates the central theme of how Judy's sense of a divide between real and ideal circuits and of the limited utility of idealized circuit theory is coupled with her emotions toward conceptual reasoning about idealized circuits within the course. The second episode consists of the next $\sim 5 \mathrm{~min}$ of the interview. Here we unpack how Judy's annoyance at idealized circuits and at what she calls "physical" reasoning is embedded within aspects of the course. And the third episode, spanning roughly the next 35 min, illustrates the coordinated context dependence of her epistemological and affective stances.

\section{A. Episode 1: Coupling real-ideal gulf, usefulness, and emotions}

The interview starts with Brian asking Judy about how the course is going. Judy states that the course is challenging since this is her first electrical engineering class while other students had taken a course or two previously. She says that to compensate she works harder than other students. When asked about what aspects of the course might be important for her future profession as an engineer, she says that she thinks that problem solving is the most important. As we will see later, this is a theme that persists throughout the interview and ends up becoming central to our analysis. Asked to say more, she responds that she does not know what a professional electrical engineer does but believes that it must involve dealing with circuits.

In these first 5 minutes of the interview, Judy seems a bit uncomfortable: her tone is hesitant, she often looks down, she often smiles nervously, and there are a few long pauses between utterances. The content of her utterances reflect that she feels vulnerable in the course as compared to other students and feels uncertain about specifics of her future profession. Judy's discomfort could be interpreted in a variety of ways: the initial few minutes of an interview can often be uncomfortable as participants (interviewer, interviewee) get a sense for one another and negotiate (often tacitly) how to frame their interaction; the opening conversation highlights Judy's struggle in the course; the conversation also makes visible that Judy's knowledge of professional electrical engineering (potentially her future job) is limited and uncertain.

To delve further into her sense of what circuits knowledge a professional electrical engineering might need, Brian asks Judy to imagine a professional engineer, "Diana," who is taking a basic circuits course to reinforce her understanding of circuits in preparation for a new job assignment. Specifically, Brian asks what a perfect version of the Basic Circuits course would look like for that engineer:

[05:16] Judy: (gazing downward) uh. okay. well, I think, ummm, the course should talk more about, um, how the, actual, world works. Because, sometimes we talk about, like, ideal circuits and, um uh (frowns, and makes a quick flick of gaze towards Brian and then lowers it again) theoretical methods. Those are not related to the actual circuit and those kind of things. So, if (slight smile) the professor can talk a little bit more about the actual circuit and how those work, then it may be better for her. (sighs and relaxes to a less alert posture)

[05:55] Brian: Why is that difference important to you? [05:57] Judy: Um, (smiles slightly) Because the ideal world is different. (laughs as she utters the last words) [06:02] Brian: Ok

Judy: yeah.

[06:13] Judy: Um, and, sometimes we talk about, um, the physical aspects of the circuits. Um, but I feel like when you really work on circuits it's-it's not very important. I mean, it's better to know what happened physically, but if those are not ideal circuits, then it's different.

Here (and elsewhere), Judy expresses the view that the "real world" of circuits operates much differently from the "ideal circuits and theoretical methods" she has learned about in class; the second is not a close approximation of the first. This disconnect, Judy posits, makes learning how actual circuits work more valuable for the hypothetical professional engineer. The emphasis in Judy's speech as she utters "really work on circuits," and "actual world works," underscores the difference she sees between working on circuits in real life and the idealized problems and discussions in the course. At times, her language reflects that the idealized and nonidealized circuits live in entirely different "worlds." In this segment, we also notice that Judy associates "actual circuits" with real world and contrasts those to "ideal circuits," "theoretical methods," and "physical aspects of the circuit." The pattern of these associations in her utterances, here and elsewhere throughout the interview, suggests that these ideas might be grouped for 
her in two different bins. Since Judy and Brian use a variety of terms, for clarity in our presentation, we will use the term "real" to qualify circuits and the world that Judy perceives to engage with in professional life or outside of classroom and "idealized models" to qualify circuits models taught in the course that make simplifying assumptions or employ qualitative reasoning (encompasses utterances of "theoretical methods", "ideal circuits", "ideal world", and "physical aspects"). We capture this notion of separation between real circuits and idealized models as an epistemological stance we label "real-ideal gulf." As we argue further, she assigns different utility and responds differently emotionally to these two bins.

Judy's reference to idealized models ("physical aspects of circuits") mirrors some prompts in the course assignments, which often asked students to present a qualitative argument for how a circuit will behave. These prompts often explicitly specified that the argument should be conceptual, not involving the mathematical manipulations of equations. In most cases, questions asking for reasoning with idealized models were followed by ones requiring calculations and looking for consistency between the qualitative argument and those numerical or symbolic computations. Appendix A shows examples of these two types of problems. Note that the language of "physical reasoning" for referring to qualitative reasoning was present in the question wording.

In this segment, we also started to notice that idealized models presented in the circuits course were likely emotionally salient for Judy. As Judy utters "ideal circuits and theoretical methods" she frowns and we interpret her facial expression as registering mild displeasure. A few seconds later, as Judy speaks about the lack of utility in understanding the "physical aspects of the circuits", she frowns again and her face pulls to a side in an expression of mild disgust. It is difficult to label her emotion here, but not difficult to register its negative valence. In Fig. 1 we show three expressions of Judy to highlight the shifts in her emotions in this segment.

In this segment, we also see glimpses that the real-ideal gulf, for her, is coupled with perceived (dis)utility of the constructs on opposite sides of the divide. Here, her statement "when you really work on circuits, it's not very important" suggests limited utility of idealized models as contrasted with the greater utility of practical knowledge about circuits ("actual circuits and how they work"). The notion of differential usefulness of specific kinds of knowledge emphasized in the circuits course-most notably, the usefulness of practical knowledge and quantitative problem solving vs the uselessness of idealized models-is also a pattern that we notice throughout the interview.

The [5:55] utterance of Brian also marks a shift in the nature of the conversation. The prompt that started this segment was meant to cue Judy to imagine a female professional engineer coming back to reinforce some skills, and Judy ends her utterance (starting at [5:16]) with a
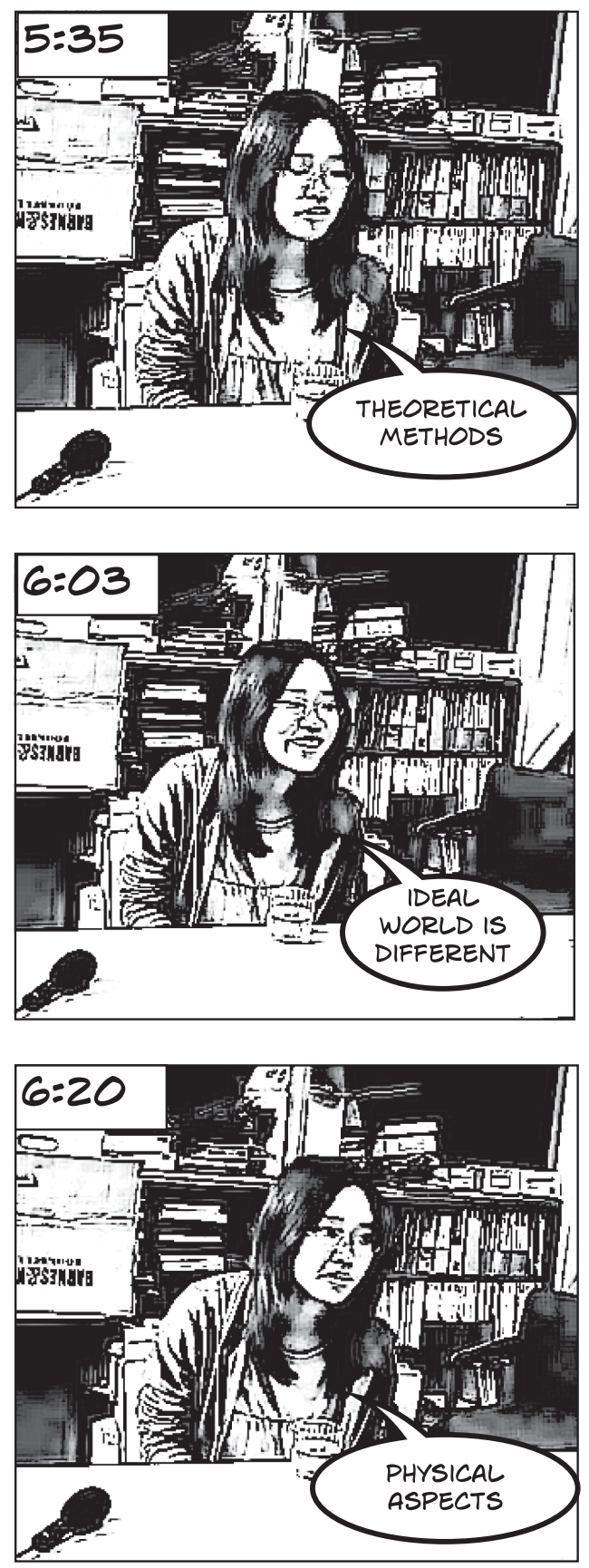

FIG. 1. The panels show Judy's facial expressions in episode 1. The first and third panel depict her negative emotions in facial expressions as she talks about theoretical methods and physical aspects. The second panel shows contrasting facial expressions during this episode.

reference to that hypothetical engineer ("...then it may be better for her."). In the next turn, Brian asks why that difference was important to Judy, herself. Judy continues to respond to that. This shift to us signals that Judy's subsequent statements about the relative importance of real circuits and idealized models is not just about a hypothetical person, but also about Judy. In saying "when you really work on circuits," Judy might also be imagining 
and referencing her own future professional life. And thus (at a higher level of inference than the data fully allow) her views and emotions towards these constructs is likely also entangled with projected and imagined future trajectories.

After Judy's utterance at [6:13], Brian asks for further clarification on the issue of usefulness.

[06:45] Brian: Hmm (pause) So do you think if you're analyzing a real-world circuit, it's still important to know about the physical aspects of the circuit?

[06:55] Judy: Not very important

[06:57] Brian: OK. What is important?

[07:01] Judy: What is important?

[07:02] Brian: Mmmhmm. Especially if you're dealing with a real world circuit.

[07:06] Judy: Know exactly how the- what's the difference between a real world circuit and an ideal world circuit, and, yeah how to deal with the real one.

It is difficult for us to completely interpret what Judy means by "not very important." Does Judy ascribe some limited usefulness to understanding idealized models? Does she use the phrase "not very" to be respectful of the course content, so as not to completely devalue that aspect of the course in front of the interviewer? It is not possible for us to tease apart these interpretations. It is clear, however, that Judy reemphasizes the distinction between real circuits and idealized models (again note the language of "real world" and "ideal world") and the value assigned to practical knowledge in the context of circuits one will encounter in the world as a professional engineer.

Brian tries to probe a bit deeper into this real-ideal gulf that Judy feels, mirroring Judy's language of real and ideal "worlds" in his question.

[08:00] Brian: When you started the course, did you have a sense of differences between ideal world circuits and real world circuits?

[08:09] Judy: No, I know nothing about circuits.

[08:12] Brian: $O K$.

[08:17] Brian: So, for you as you've taken the course, has your sense of real world and ideal world changed in any way since the beginning?

[08:28] Judy: Yeah. Yes, I now feel like many components in the circuits are not perfect. It's not like you can completely use the physical method to analyze those. [08:46] Brian: OK

[08:50] Brian: Could you say a little bit more about the physical method?

[08:53] Judy: Um, like a capacitor, I might say this wrong, but um, like they have a limit that how many currents, or how many electrons (moves left hand up and down in a chopping motion) can stay on the plate (chops both hands down). That's a real world (moves left hand up and down in a chopping motion) capacitor. But, for, ideally, sometimes in the course we assume that each plate (spreads hands apart) can have infinite amount of electrons (turns both hands palm up), and those kind of things. So, I mean, if that doesn't exist (turns left hand palm up) then why do we use that method to solve it? We are not gonna use that method in the future anyway. I mean, it's good to know, but it's...yeah.

Responding to Brian's question asking how her views have changed, Judy clarifies some of her earlier statements. We interpret her response to mean that circuit components one will actually work with have imperfections (or limitations) and that idealizations assumed within the course content will not be applicable to these components. The capacitor example illustrates this: a real capacitor cannot hold infinite charge. Based on this, Judy rejects ideas and results based on idealized models of circuit components, since those ideas or results will not be applicable in her future as a professional engineer.

In this excerpt, we again find Judy binning together ideal world, idealizations in circuits, and the "physical method". Her statement of "it's good to know" is reminiscent of her statement from the earlier segment, "it's better to know." Here again, we find it difficult to interpret what value she is attaching to idealized models, having rejected it in the statement just preceding it [8:28].

Judy's sense that real circuit components behave differently from the idealized models could be a healthy skepticism; many expert engineers will also hold that view. But for experts that skepticism is typically balanced with a view that idealized models generate productive approximations and starting points for the design of real circuits (or other systems) [72]. Judy, by contrast, takes the stance that conceptual reasoning about idealized models of circuitsbecause of their distance from the real world — will be of very limited use for someone working on a real circuit.

Brian probes a bit more on how this difference between real and ideal circuits plays out in her Basic Circuits class.

[09:52] Brian: In the class, have you ever done comparisons of-say for a particular circuit, looking at the way a circuit behaves ideally and the way it behaves in the real world?

[10:03] Judy: Yeah, um, but we don't focus on that. Sometimes the professor will mention the difference between these two, but that's not the main part of the course.

[10:23] Brian: And um, do you think that...Do you think that in a sort of perfect version of the course that that would be a main part of the course? Talking about comparing ideal-world and real-world circuits?

[10:38] Judy: Um, I-I want it to be focused on the real world. And then you can mention the difference between the real world and the ideal world. Yeah. I think we should focus on the other way, not...

Judy mentions that while the instructor has at times discussed the difference between real circuits and idealized 


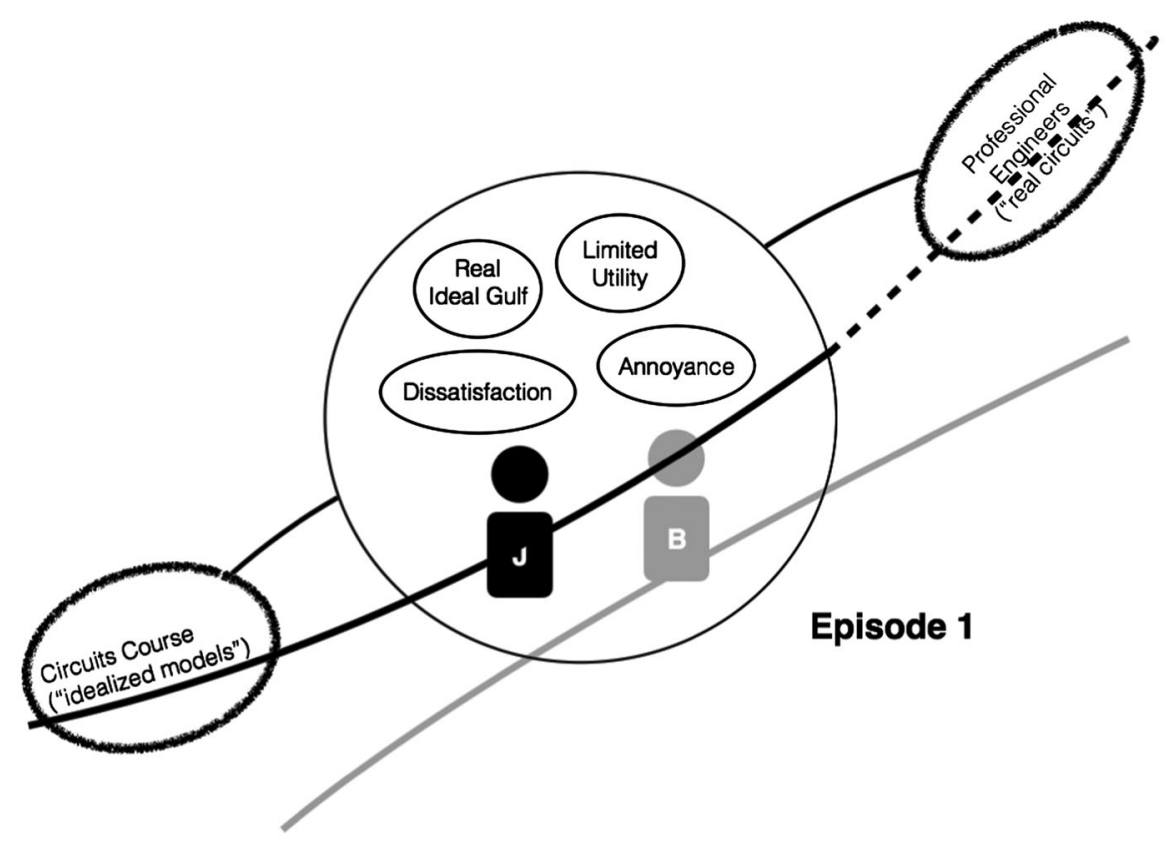

FIG. 2. Visual representation of the model for episode 1. Judy (marked as J) and Brian (marked as B) are shown as co-supporting the aspects of the interview conversation that we model labeled as real ideal gulf, limited utility, dissatisfaction, and annoyance. Judy's trajectory through time (thick black line going through "Judy") is shown as moving through past experiences in the Basic Circuits course, through the present time of the interview, into the projected future (represented by dotted black line) of participating in community of professional engineers. It is highlighted (via thin connecting lines between the bubbles corresponding to the course, the interview, and projected professional engineering future) that in the interview, the course is positioned as having a focus on idealized models and professional engineers as being focused on real circuits. Real ideal gulf here refers to the epistemological stance of separation between real circuits and idealized models. Limited utility refers to the sense that idealized models are of limited utility to professional engineers in analyzing real circuits. Dissatisfaction refers to the sense of dissatisfaction at the circuits courses' emphasis on idealized models. And annoyance refers to the negative emotions Judy expresses when talking about idealized models.

models, it was not a principal theme of the course. For Judy, the ideal version of the course would start with a focus on real circuits and then maybe introduce idealized models as and when needed. Judy's desire for the course to focus on real circuits again highlights the difference she sees between real circuits and idealized models and her perception that knowledge of real circuits is more important. In the next $3.5 \mathrm{~min}$, Brian asks Judy if she has some advice for the hypothetical engineer and how the course could better meet the needs of the hypothetical engineer. Judy says that the course could start with analysis of circuits that are used in companies rather than idealized models.

Summarizing episode 1-The hypothetical of a returning professional engineer spontaneously brings up Judy's sense of real-ideal gulf (separation between real circuits and idealized models) and her sense that as a professional electrical engineer knowledge about real circuits is what she will use. This sense seems to be coupled, at least conversationally, to her dissatisfaction with the course's focus on idealized models. And there is evidence that this dissatisfaction is associated with a feeling of annoyance. We present the summary of our analysis in Fig. 2. Inspiration for the visual representation comes from representations of narratives by Cole [73], with help from our colleague Turpen [n.d., personal communication]. We model the epistemological and emotion aspects we highlight in the interview conversation as supported in the interaction between Brian and Judy, even though we are not modeling in our analysis how Brian is playing a role in stabilizing these stances. We get to this point towards the end of the article. Also, consistent with the analysis presented above, the interview conversation is shown as explicitly connected to Judy's experience in the circuits course and to her projection of her participation in professional activities in the future.

In what follows, Brian's and Judy's conversation further explores how idealized models are embedded within the course structure, and how Judy feels about these course features.

\section{B. Episode 2: Judy's annoyance is associated with features of the circuits course}

Brian next prompts Judy to think about the structure of questions in the course assignments:

[15:30] Brian: I am gonna change topics just a little bit. Judy: Okay

[15:33] Brian: A student whose opinion I heard earlier from your class had noticed that the homework and tests seemed to contain two sort of types of questions-two different kinds of questions. And I was wondering if it's 
been your experience that you've noticed something like that.

[15:51] Judy: Oh, you mean like a physical question. Like, a theore-more like a theoretical question?

[15:57] Brian: Umm, I'm not sure. They didn't elaborate much, so I was trying to get a sense of what your sense was.

[16:01] Judy: Oh. I think, um, you mean two parts, right? Umm, I think one of them is like, um, just problem-solving. Like, you have a diagram (spreads hands out, gently taps table with fingertips) and then you solve for the current or voltage. Um, and the other type is like (shakes head gently side-to-side) a physical question. They will ask you what is (shakes head) physically (pinches thumb and forefingers of both hands together, moving her hands up and down) happening in the circuit, and you have to explain them in (shakes head slightly, left to right) words.

[16:31] Brian: OK.

[16:33] Judy: Um, because, um, I am also doublemajoring. My second major is physics, so I guess it's good to know more about like, what's physically happening (pulls her mouth to side) in a circuit. Like for me, cause I'm-that's my major. But, if, um-for a student who's just doing an EE major, I don't think that's very necessary.

Judy's first reaction is to clarify if Brian is asking about the physical or theoretical questions, reinforcing our sense that these terms represent closely associated ideas for her within the course context and supports our act of lumping these terms used by Judy under an umbrella term of idealized models. Next, Judy clarifies that Brian might be referring to two distinct (in number and quality) parts to the same question. Judy then distinguishes between course assignment questions focused on idealized models (what is physically happening in the circuit) and those focused on mathematical calculations ("problem solving", "you solve for the current or voltage").

In her verbal and paraverbal utterances here, we draw out two themes we have seen before, epistemological and emotional. First, she ties the "physical" questions to their limited utility for an electrical engineering student. Her stance here matches what we saw earlier: idealized models can be "good to know" but have limited practical use (what we modeled in Fig. 2 as "limited utility"). Here, one new aspect we hear is Judy's status as a double major and her associated sense that knowing idealized models could be useful for a physics student. A high-inference interpretation here would be that the value divide she articulates-knowledge of idealized models of circuits could be useful for physics majors but not for engineering majors-derives from some deeper epistemological discontinuity she sees between physics and engineering and/or between her future trajectories through these disciplines.

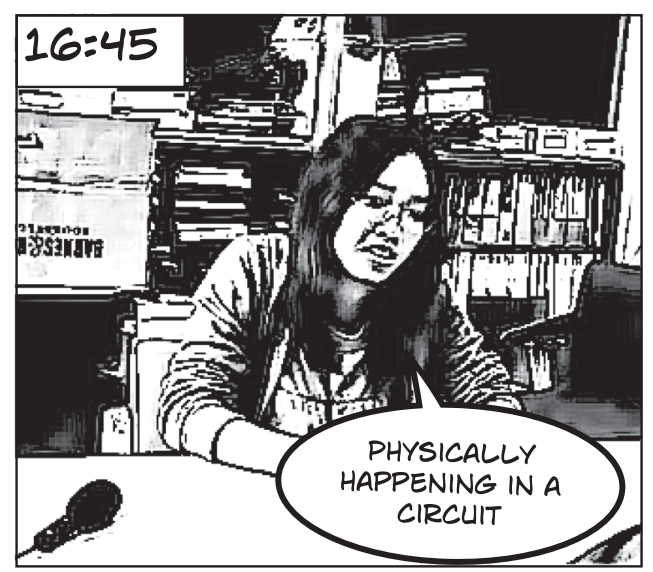

FIG. 3. The panel shows the negative emotion in Judy's facial expressions in episode 2 as she says "physically happening in a circuit."

Second, we notice various facial, gestural, and tone markers displaying her annoyance as she talks about the "physical question[s]." Figure 3 shows her expression at time stamp 16:45, right at the moment she utters "physically happening" in the transcript above.

Finishing her last utterance [16:33], Judy explicitly labels these questions as "annoying":

[17:03] Brian: OK. So, do you think if there were other students like you who were double-majoring in, say, physics and EE, that you would suggest the same thing to them?

[17:13] Judy: Yeah. I mean those questions are-it's (shakes head gently, but repeatedly) kind of annoying (smiles). But it's good to know (rise in voice tone).

[17:24] Brian: What is it that makes them annoying? [17:25] Judy: It's hard to under-to understand or to answer. It's, umm. Yeah maybe we don't know enough about physical things. Because, in class we don't talk about those. We don't-in class we just do the problemsolving part. So, um, yeah. It's hard to answer. I know many people, um go to the professor's office hours just asking those physical questions.

[18:10] Brian: Have you talked directly with anybody who has a hard time also answering the physical kind of questions?

[18:16] Judy: Umm, yeah, but we didn't talk much.

[18:22] Brian: Hmm, OK.

[18:23] Judy: Uh, yeah. know they feel annoying too. [18:29] Brian: OK.

Judy's statement that the questions focused on idealized models were annoying was spontaneous. Judy's facial expressions and movements show a range of variation in this segment (Fig. 4): from reflecting mild displeasure (such as shaking her head when talking about her annoyance), to smiling (for instance, right after mentioning that the questions 

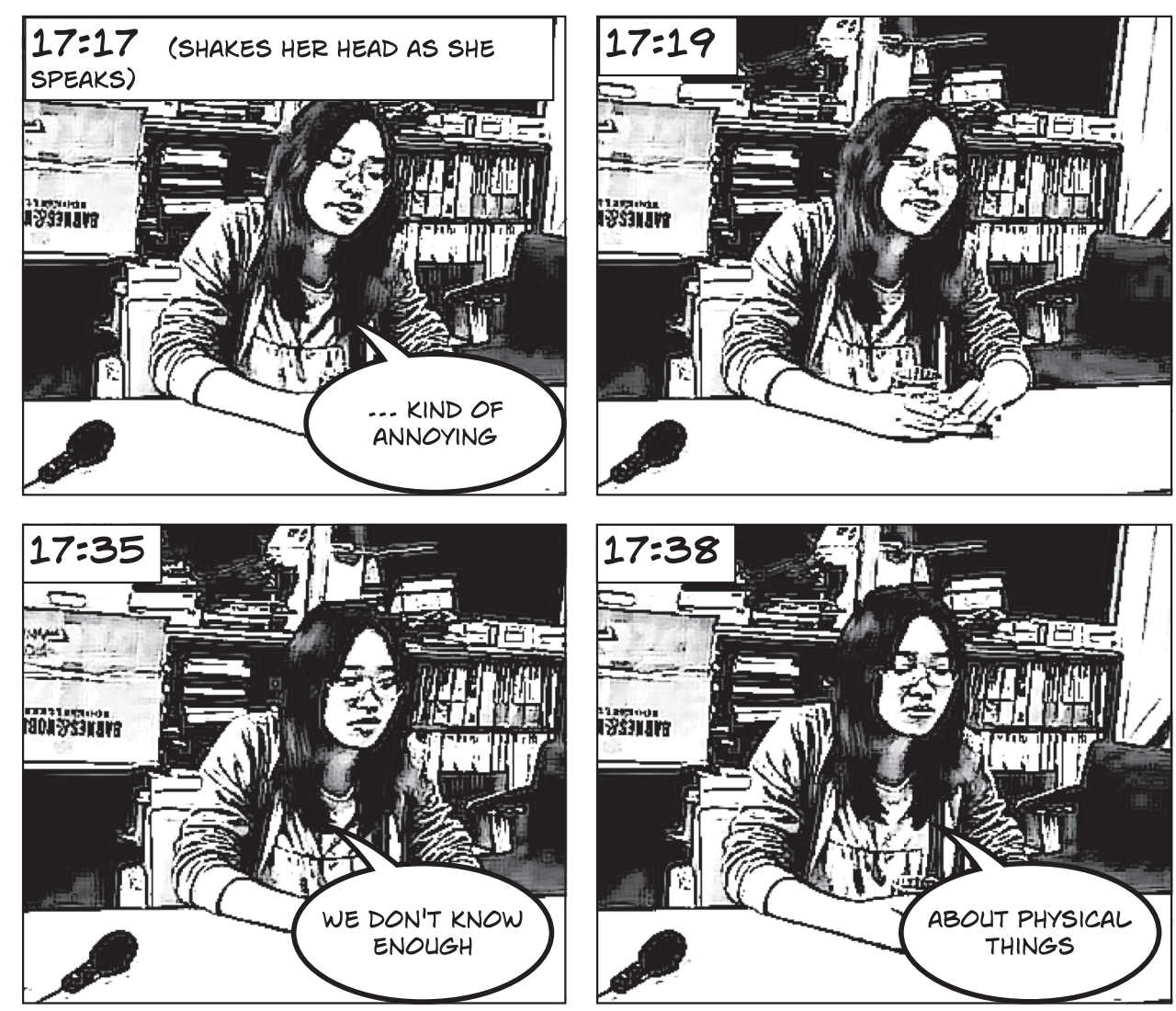

FIG. 4. The panels show the range of Judy's facial expressions in episode 2 as she discusses the conceptual questions being annoying.

are annoying), and at times reflecting embarrassment. Not all of her physiological reactions are similar to those in the previous episode, when they depicted a starker negative emotion; but, in this episode, Judy is reflecting upon her annoyance rather than (re)experiencing it as it first arises in the conversation in episode 1. So, "annoyance" takes on a slightly different ontology in episode 2 . As an emotion word in an utterance, it references and describes her past emotional state connected to the questions focused on idealized models. This differs from inferring her in-the-moment emotions using physiological and paraverbal modalities, as in episode 1 . In episode 2, we expect that some of her in-the-moment reactions, such as the head shaking, would reflect the emotional state she is reflecting upon, perhaps "dampened" by regulation based on her being in the interview context with someone she just met. ${ }^{2}$

The continuity in this epistemological-emotional theme across episodes makes a plausible case for labeling the

\footnotetext{
${ }^{2}$ Here's why these distinctions matter. The case we are building in episode 2, mainly through Judy's utterances, is that she reports feeling annoyed at questions on idealized models (physical questions), and we aim to unpack how that annoyance connects to the course structure. In episode 1, by contrast, we were building the case that her in-the-moment physiological reactions indicated a coupling between her in-the-moment emotions and her perception of a real-ideal divide and of the limited utility of idealized models.
}

in-the-moment emotions of episode 1 as annoyance and as connected to the emotion-word, "annoyance," Judy uses in episode 2 when reflecting on her past emotional state.

We can also see glimmers of the structural forces that play a role in the generation and sustenance of Judy's annoyance. Judy's annoyance at questions on idealized models seems to stem, in part, from the lack of instructional support that she perceives for answering those questions, especially since she sees these questions as difficult "to understand or to answer." The paucity of support, she says, contributes to her lack of success in answering those questions.

We should note that success on assignments is linked to getting a good grade (the assignments contributed towards the final grade), which in turn links to opportunities for jobs and internships. For these reasons, a repeated lack of success on the questions focused on idealized models could potentially generate the annoyance that Judy mentions, hinting at how instructional structures and institutional policies influence emotions (and epistemological stances). Over time, such annoyance could become coupled with the sense of the gulf between real world circuits and idealized models as well as the limited utility of the latter. Judy here recruits support for her annoyance by claiming that her classmates share this emotion. If Judy perceives that classmates share the annoyance she feels towards the questions on idealized models, that might serve to legitimize and amplify — and thereby reinforce - that emotion. 
Following this exchange, Brian turns again to explore the relevance of these questions for the professional life of an electrical engineer:

[18:32] Brian: So, um, this is a-this is a sort of difficult question, but, um, with our imaginary person Diana, who's the professional engineer. Do you think she would probably find that those questions are tough also?

[18:47] Judy: Yes, I guess.

[18:48] Brian: OK. Why do you say that?

[18:50] Judy: Because [shakes head gently, but repeatedly, left-to-right] those physical questions are not very related to the actual world; not related [knits brow] to her job. So...that's why I say it's not very necessary for student[s] who are only in EE major to learn those parts.

[19:22] Brian: Do you think one kind of question is more helpful to you than the other kind?

[19:28] Judy: Umm, yeah I think the [cocks head, smiles] problem solving is more helpful [laughs] and [nods] more important.

Much like her stance on idealized models, the assignment questions on idealized models are also of limited utility for Judy when considering the work of an electrical engineer. Judy's careful specification of "students who are only in EE major" tentatively suggests that she is still thinking that these questions could be useful for physics majors. What is more, those questions, for Judy, are unrelated to real circuits. Like knowledge about real circuits, it is equation-based problem solving that she thinks is more useful for electrical engineers. Thus, the relationship between and the relative utility of problem solving vs "physical questions", as well as Judy's associated emotions, closely mirrors the gulf between real world circuits and idealized models and her associated emotions.

So far, we have built a case that Judy perceives a gulf between the real world circuits she will encounter as a professional electrical engineer and the idealized models emphasized in the Basic Circuits course; she perceives that knowledge about idealized models is of limited applicability to real world circuits, while mathematical problem solving is useful for dealing with real-world circuits. She is annoyed by the course's assignment questions on idealized models, and she feels a lack of course support towards successfully answering these questions.

Episode 2 sheds further light into how aspects of the conversation in episode 1 modeled in Fig. 2 are linked with course features and experiences, without fundamentally altering any relationships between the modeled elements. As such, we do not present a new visual representation for our analysis of episode 2 .

Next, we examine the stability and persistence of these stances and emotions through shifting conversational contexts during the rest of the interview.

\section{Episode 3: Co-occurring context dependence in emotions and epistemology}

As the previous segment closes, Brian asks Judy about how she knows when she understands an equation. Judy replies that she would typically review notes after class and try to work out a couple problems to make sure she understands the material. Brian next asks her what she does if she does not understand an equation:

[21:28] Brian: Have you ever been working on a problem, and thought uh-oh, wait a minute, I don't think I get this equation?

[21:48] Judy: Um, Yes. Um, Very frequently (smiles with aspiration). Um... Then I would go back and look at my notes try to figure that out. And, you know, moreum, think more about the equation think more deeply. Um. Think about the physical aspect (pulls back her head and smiles, a bit sheepishly).

[22:04] Brian: Do you actually think about the physical aspect of the equation?

[22:07] Judy: I try to use the physical aspect to help me to learn and really understand an equation. Sometimes it doesn't work, though (laughs).

Brian: could you talk a bit about when it works and when it doesn't

[22:25] Judy: Um, Sometimes it will just make me feel more confusing, and I will end up to go to the professor's office hours (laughs). Sometimes it works (laughs). And...yeah.

[22:49] Brian: In those moments, how do you know or how do you get a sense of "uh-oh. I'm not getting this." It sounds like it's happened several times for you. How do you know in the moment that that's what's happening?

[23:02] Judy: Umm...Like, like you can look at a circuit from many different ways. And if I look at a circuit from one way, and then I get a result-say I get the voltage across a capacitor. And then I use another way to look at the circuit and get a different result, then I "oh" and "maybe I did something wrong." And, yeah.

Judy seems aware and a tad embarrassed at frequently encountering difficulties in the course, but also seems to have a way of dealing with it. Perhaps surprisingly, given her earlier statements, she says she would try to use idealized models (the "physical method") to figure out the equation at a deeper level, when she does not understand the equation sufficiently. It is unclear here what she means by "think more deeply" or "really understand an equation", or how she uses idealized models to make sense of an equation. The next segment, where she solves and explains a circuits problem, can give us a sense for what she could have meant. More important is her emotional reaction when she says that she uses the "physical method". She pulls her chin back, which lowers her gaze, and her tone changes. It is difficult to 
Think about the following circuit

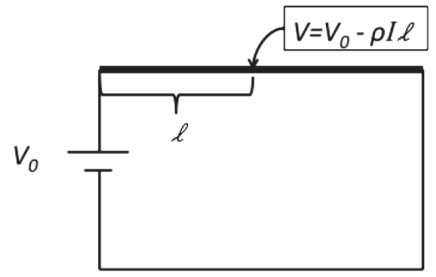

The voltage potential at any point along that wire with resistance of $\rho$ per $\mathrm{cm}$ is given as $V=V_{0}-\rho I l, I$ is the current through the wire and $l$ is the length from the battery end to the position at which voltage potential is measured.

How would you explain that equation to a friend from class?

FIG. 5. The prompt given to Judy for the extended resistor problem.

describe tone in an objective manner or from a frequency profile of the audio signal, but her reactions here seem to indicate some degree of embarrassment. Her reaction is not surprising given that, a few minutes ago, she labeled idealized models as useless and annoying. In her next conversational turn, she does acknowledge that the "physical method" does not always work to resolve her confusion. As she acknowledges that the strategies based on idealized models can work sometimes, she laughs. This contrasts starkly with the annoyance displayed when she mentioned going to office hours for help with the questions focused on idealized models assigned in homework. But alternative interpretations to this admittedly high-inference interpretation could be plausible. It is possible that Judy's sense of the utility of idealized models is nuanced: maybe she holds the belief that idealized models are useful for understanding equations but not for understanding real world circuits. However, if it were a simple case of "usefulness" taking on different values in different contexts, why would she be embarrassed to admit that she uses this when trying to make sense of a confusing equation? Her reactions in this segment, to us, seems an acknowledgement of her awareness of her departure in this moment from her earlier stances towards idealized models.

In the next 4 min, Brian and Judy talk a bit more about trying out multiple problem-solving methods. During this, Judy shares that part of what makes her comfortable with an approach is familiarity, but also ease of solution or a shorter solution path. Then Brian poses a circuits problem, shown in Fig. 5. We designed it to probe how students make sense of a nonstandard statement of Ohm's law for an extended resistor.

Notice that the problem involves an abstracted idealized resistor; but in its form, it looks more like a regular textbook end-of-chapter problem. The real-life analogue might be a slide potentiometer or a linear variable resistor, but real-life connections never come up in Brian's and Judy's conversation.
When posing the question, Brian first tells Judy that he would be asking her to think about a circuit and wants her to talk him through how she is thinking. After Judy reads the question, Brian asks her how she would explain that equation to a friend. Judy says she would first explain what the different variables are:

[27:43] Judy: First I would just repeat this equation, then explain what rho is, what I is, what L is. And then, I guess rho $I$ and $L$ is somewhat related to the resistance (questioning tone) of the wire (questioning tone). So, I will explain that to him. And then, this is-yeah, I guess rho and $L$ is kind of proportional to $R$. This question is basically just like, I equals $V$ over $R$. It's actually a lot more easier question than it looks like (slight smile). Yeah.

Judy is telling Brian what she would explain to a friend while simultaneously making sense of the question for herself. Also noteworthy is that her emotions are fairly neutral, even though she is working through an idealized circuit. At the end of that utterance, when she reflects that the question is easier than it initially looked, she smiles slightly, indicating a slightly positive emotion. Overall, this positive emotion continues in what follows.

[28:40] Brian: How did you know that rho and $L$ were related to resistance?

[28:45] Judy: Because I learned that before (laughs). And it looks like also kind of proportional to the, um, V. Yeah, so. I have a theory.

[29:05] Brian: You say it looks like it's proportional to V? [29:14] Judy: Yeah, proportional to the voltage difference between the battery and the point-some position on the wire.

[29:23] Brian: What's leading you to think that?

[29:29] Judy: Rho is just a constant, right? And L is like a variable. And I is a constant, I guess. So, um. If I plot this equation, it would be like a line-a straight line, going down.

We see Judy as engaging in lots of productive reasoning. In [28:51] Judy draws on proportional reasoning to help connect this equation to Ohm's law. This relates to her previous utterance where she says that "rho" and "l" are related to the resistance of the wire. And in [29:29], Judy starts to represent that equation graphically. In other words, Judy is blending elements of her knowledge about circuits (resistance, Ohm's law) and about mathematics (proportional reasoning, graphs, linear equations) to make sense of the equation. Here again, her emotions are neutral or positive (laughter in [28:51], Fig. 6).

Judy continues to make sense of the equation, using proportional reasoning to argue how the voltage would vary with length along the wire. After that, Brian asks Judy to reflect on the kind of reasoning she just did. 


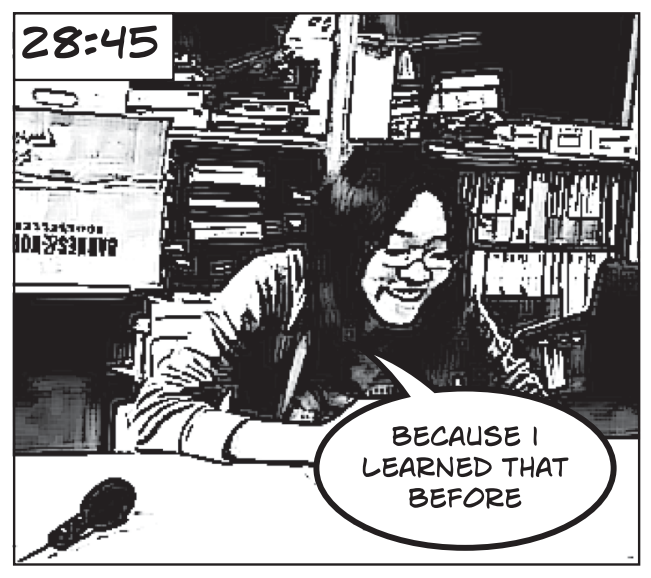

FIG. 6. Judy displays positive emotions in facial expressions as she works on the extended resistor problem.

[34:03] Brian: Thinking about it in this way-is that a way that you're used to thinking about it.

[34:13] Judy: I usually don't use this way. Because it's more like a pure math way. But I want to use more physical way to think about it.

[34:35] Brian: What might be a physical way to think about it?

[34:42] Judy: Actually figure out why there's a rho and an $L$ in the equation, and then that will lead me to $R$, which is more familiar equation that I usually use. So then that would help me to understand what does this term actually mean.

[35:13] Brian: If you do start to ask yourself why there is a rho or an $L$ in the equation, what do you start thinking about?

[35:25] Judy: Resistance. I mean, when I look at rho, I know that's a property of the wire, so that will lead me to $R$. And that reminds me of the equation relating $R$ to $L$ and rho..yeah

[35:58] Brian: So it sounds like what happens is that you see parts of the equation that remind you of parts of other equations?

[36:17] Judy: Well, of what I learned in physics class.

In responding to Brian, Judy says that to make meaning of this equation for herself, she wants to "use more physical way," clarifying that she would want to connect rho and $L$ to the resistance of the wire. To her, that would give more meaning to the last term in the equation. This connects back to her previous statements when trying to explain that equation. The equation Judy is referring to is $R=\rho l / A$, (where $A$ is the cross-sectional area of the wire and $\rho$ is the resistivity of the wire), which is an idealized equation. And we see Judy drawing on her physics knowledge for this problem.

Here is our point: When talking about or engaging in equation-based problem solving, Judy displays positive emotions: she smiles and laughs and does not appear to be tensed. Also, we find no evidence that in these moments she is ever thinking about the separation between real circuits and idealized models ("real-ideal gulf"). In other words, as the conversational topic shifts, there are cooccurring shifts in Judy's emotions and epistemology. We do not mean that she has shifted to a stance where real circuits and idealized models are connected, but rather, we note the disappearance of the theme of real-ideal gulf from the conversation.

In the rest of the interview, Judy works through two more circuits questions: one about a resistor-capacitor series circuit and another about voltage waveforms. During the resistor-capacitor problem and while answering associated follow-up prompts on series and parallel circuits, Judy engages in reasoning through the Ohm's Law equation as applied to that circuit, drawing on proportional reasoning when needed to explain the equation. She and the interviewer, Brian, never bring up if these problems are relevant to future professional work. By contrast, she indicates twice that she is drawing on knowledge learned in the Basic Circuits and in introductory physics courses, such as capacitor impedance, mesh analysis, and resistance in series and parallel circuits. Throughout, Judy displays positive emotions (indicated by smiling, laughing, relaxed tone of voice) and focused on the circuits' reasoning.

In the last segment of the interview, Brian asks Judy a question on voltage waveforms culled directly from a course assignment Judy had completed (see Appendix A).

[50:06] Brian: Suppose you were comparing, um, three different types of waves in a circuit. So, you're comparing a sine wave, a square wave, and a triangle wave. And all three of them have the same RMS voltage. Which one has the highest peak voltage?

[50:36] Judy: \{sighs, smiles\} Um, triangle wave.

[50:39] Brian: OK. How do you know?

Judy talks about how she had found this question particularly challenging, forcing her to turn to her physics TA for help. She summarizes what she remembered of her TA's explanation, acknowledging that she cannot remember it fully, and then turns to an equation. She talks about how the answer has something to do with the integral, which is "related to" the area under the curve. Overall, her emotions in this segment are really positive; she laughs and smiles quite frequently and makes more eye contact with Brian than in some of the previous segments. Brian then presses her to think it through for herself. In response, she does some excellent informal reasoning:

[52:58] Brian: So, if you didn't have your book, but you know there was some relationship between the integral and the area. Is there a way that you could think through this? 


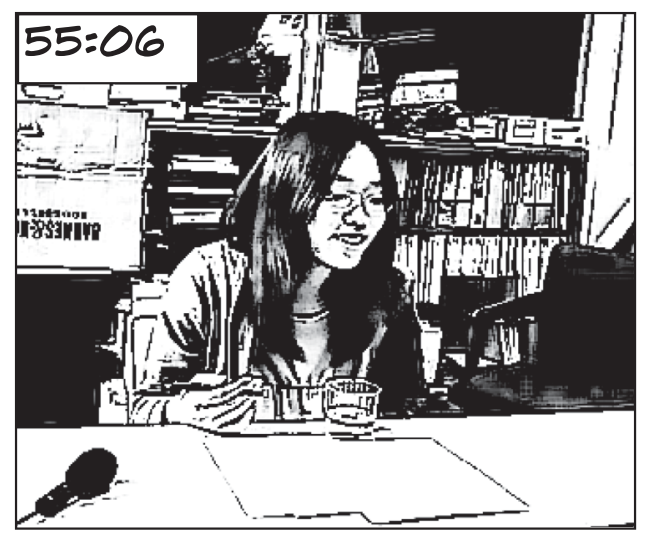

FIG. 7. Judy displays positive emotion in facial expressions after successfully solving the conceptual problem on waveforms and their RMS voltage.

[53:07] Judy: Um. \{6 second pause\} I guess-I mean I can try. So they have the same period like from, uh zero to $T$. So the integral would be like from zero to $t$. Um, and then they have some kind of wave form here. And they have a same answer. So. \{5 second pause\} I dunno. I mean, if they have the same area, um and, this part is like the same length, um, because like. This looks like wider \{spreads hands apart, past her shoulders\}-like the area looks wider \{spreads hands again\}. So there should be, like. If you squeeze it into \{presses palms toward each other\} this form, it should be like, going up \{forms a peak with her hands\}. So, it should be like this. So, apparently, like, they have a higher peak.

Judy here is thinking of the area under the curve as a kind of squeezable stuff; since the area under the three curves is the same, the amount of stuff is the same, and when you "squeeze" a rectangle (square wave) into a triangle (triangle wave) of the same base length, the triangle ends up with a "higher peak." Then Brian probes her stance towards her reasoning:

[54:42] Brian: But I'm interested in that you said "squeezing." \{Judy laughs\} Do you ever, um, ever um think about the mathematics that you use in that way? [54:53] Judy: \{Judy smiles\} No, I never think of that before. That's the way how the-my TA told me. Yeah, I mean it's I feel like it's not very formal \{smiles\}, but it's very useful.

Our transcript does not capture the satisfaction-evident in the video-she felt about her solution. Figure 7 shows her facial expressions at this moment.

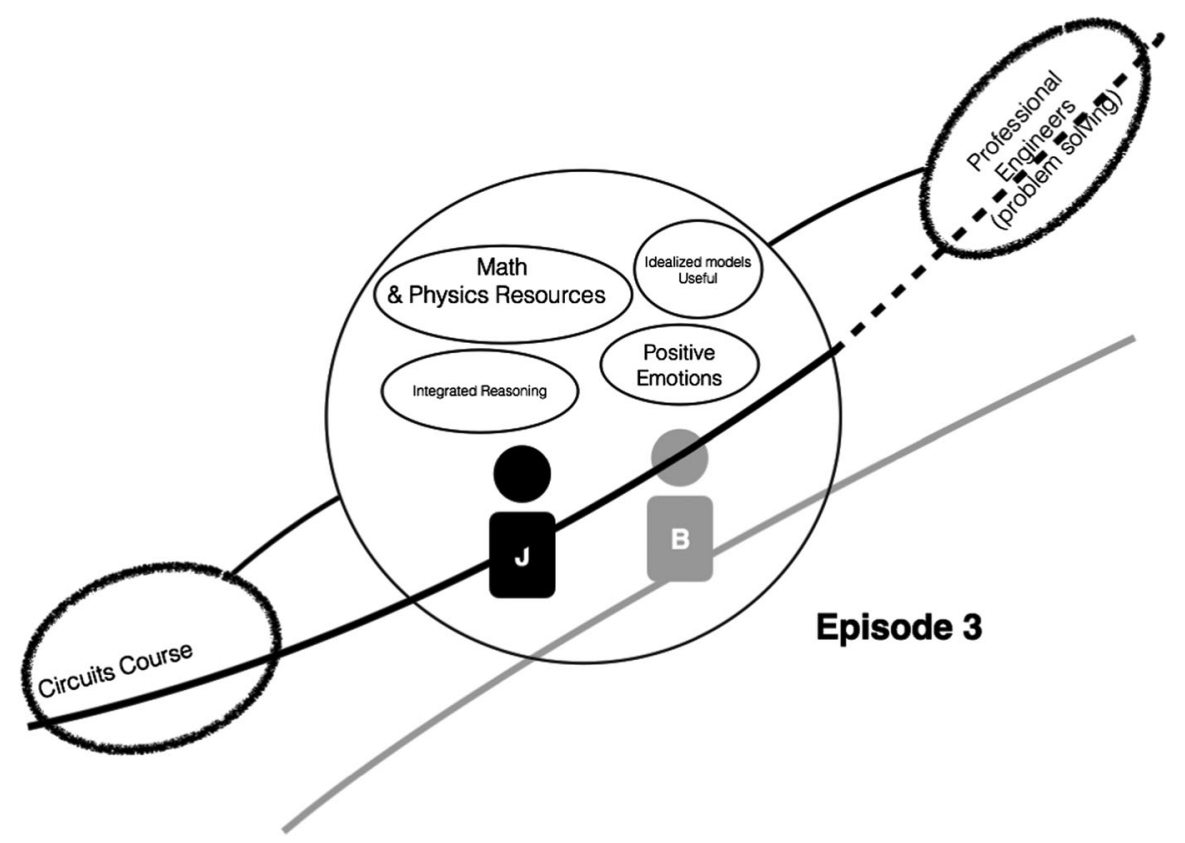

FIG. 8. Visual representation of the analysis of episode 3. Judy (marked as J) and Brian (marked as B) are shown as co-supporting the aspects of the interview conversation that we model labeled as "Math and physics resources," "Idealized models useful," "Positive emotions," and "Integrated reasoning." Judy's trajectory through time (thick black line going through Judy) is shown as moving through past experiences in the Basic Circuits course, through the present time of the interview, into the projected future (represented by dotted black line) of participating in community of professional engineers. Math and physics resources here refers to the conceptual knowledge elements that Judy is drawing on in order to solve problems. Integrated reasoning refers to the epistemological behavior where idealized models and conceptual reasoning are integrated in her problem solving. Idealized models useful refers to the epistemological stance that idealized models are useful. That the elements modeling in the "interview" space have links to past course experiences and the projected future as a professional engineer is highlighted via thin connecting lines between the bubbles. 
Since the interview had now run for almost an hour (the time we had advertised), Brian closes the interview here.

While solving this last problem, Judy's emotions are strongly positive, in contrast to the annoyance displayed in episode 1 and discussed in episode 2. Here, however, she was solving a problem of the type she had earlier called annoying. Also interesting is Judy's describing the "not very formal" reasoning she just employed as "very useful." The data do not allow us to determine to what purpose she considers this kind of reasoning useful. The stance, however, seems consistent with her earlier statement about trying out idealized models if another way of solving a problem does not work out or if she needs to understand an equation better. A model of the conversation in episode 3 is presented in Fig. 8.

\section{Interview summary: Co-occurring shifts in epistemology and emotions}

In summary, we see co-occurring changes in conversational topic, epistemological stances, and emotions, finely coordinated in time during the transition from episode 2 to episode 3. When talking about the course in the context of future trajectories, Judy perceives a gulf between real circuits and idealized models, regards the course focus on idealized models to have limited utility towards understanding real life circuits, and finds homework problems focused on idealized models to be annoying. This annoyance is linked to the limited instructional resources she perceives to be available for achieving success on the assignment questions. At these moments, Judy's negative emotions are indicated not just by her statements by but also by facial expressions, tone of voice, and posture. As the context shifts to solving circuits problems, her emotions shift towards being positive; she smiles and laughs a lot more and makes more eye contact with Brian. She acknowledges that she turns to idealized models if she is stuck on a problem or if she wants to understand an equation better, though it does not always help her. When solving the first two problems she does engage in mathematical sense making around equations, drawing not just on manipulations and functional dependence (e.g., proportionality and inverse proportionality) but on how they relate to circuit characteristics. Her enacted epistemology in these moments is that reasoning with idealized models can be useful for solving problems. Finally, after she completed two problems that she took to have a form similar to regular equation-based circuits problems, Brian turns to a problem that has the same structure as the assignment questions she finds annoying. However, her positive emotions persist. She acknowledges the problem as one she had struggled with and had sought help from her previous physics teaching assistant. She tries to find a formal way to solve the problem, but she cannot remember the needed equations and does not have her notes or textbook. Prompted by Brian, she engages in good conceptual reasoning about an integral to successfully solve the problem. Furthermore, she acknowledges that this kind of reasoning can be productive, albeit with a distancing hedge that she does not often engage in that kind of reasoning.

So, in the problem-solving segments of the interview, Judy consistently displays positive emotions and the epistemological stance that idealized models can be useful, and the real-ideal gulf no longer appears in her utterances.

\section{DISCUSSION AND IMPLICATIONS}

\section{A. Have we shown that Judy's emotions are entangled with her epistemology?}

Did we successfully achieve our goal of arguing that Judy's emotions are entangled with her epistemological stances? After all, is it not possible that Judy's epistemological stances towards real and ideal circuits are simply changing with context and her emotions are merely epiphenomenal (along for the ride)—a "cold cognitive" model [9]?

To address this question, we reconsider the shift in Judy's emotion and cognition that occurs when the interview topic changes from talking about idealized models to solving the first circuits problem. In a "cold cognitive" account, Judy's epistemological stance towards the gulf between real circuits and idealized models is active in the initial parts of the interview and inactive (or not made available in talk) during problem solving. When this stance is active, it invokes the stance that idealized models are not useful. By contrast, during problem solving, an activity she thinks is useful towards future professional goals, she sees idealized models as productive for understanding equations and as a back-up strategy for solving problems and draws on it. ${ }^{3}$ In this purely "cold cognitive" explanation, Judy's annoyance when talking about idealized models and positive emotions when problem solving are simply byproducts; they play no explanatory role.

In our alternative account, by contrast, emotions help to explain the stabilities and shifts in Judy's utterances and behavior. By this account, Judy's experience of difficulties solving the conceptual homework questions versus her comfort and success with the more typical problems, her feeling of receiving insufficient instructional support to answer those questions successfully, and her sense that other students resonate with her feelings play a large role in generating and sustaining annoyance at the questions focused on idealized models. In the interview she talks about this annoyance along with experiencing negative emotions when talking about idealized models. In our

\footnotetext{
${ }^{3}$ When solving the circuits problem, Judy does rely on idealized models about the circuit to make sense of the modified Ohm's law equation. The reasoning she mentioned when talking about the capacitor example differs from the kind of reasoning she employs when talking about how resistance might depend on physical parameters of the resistor; but both draw on idealized models.
} 
alternative account, the negative emotion sustains the realideal gulf and the limited utility of idealized models for her professional goals - perhaps for the following reasons: the epistemological stances not only distances her from object of negative emotions but also serve to justify her emotions.

By this "hot cognitive" account, when the context shifts to problem solving, Judy's emotions shift, in part due to prior positive emotional association with problem solving for Judy. If earlier in the interview her annoyance was sustaining the epistemological stances towards real-ideal gulf and limited utility of idealized models, then a new context that invokes positive emotions (and inhibits annoyance) should make it easier (or more likely, but not determine) for Judy to draw on and value idealized models and likely decrease the salience of the real-ideal gulf in her talk. Which is exactly what we observed.

However, the data are unable to support one of these accounts more strongly than the other. And more generally, we suspect that some phenomena explained by integrated emotional-cognitive dynamics - a "hot cognitive" account - might also be explained by a sufficiently nuanced, layered "cold cognitive" account in which emotions are merely along for the ride.

In light of this empirical underdetermination, our point is this: the "hot cognitive" account is no less plausible than the "cold cognitive" account. In spite of the cold cognitive account being simpler (fewer elements to model and consider), this empirical underdeterminacy warrants consideration of the "hot cognitive" account by researchers and instructors because of the other advantages gained, as we outline now. Integrating conceptual, epistemological, and emotional dynamics at the fine timescale can have particular affordances. For one, it can help us build towards the original vision of a complex cognitive ecology [74]. In laying out a model for integrating emotions into fine time scale dynamics of reasoning, it opens the doors for further expansion to integrate constructs such as identity into the fine timescale dynamics of reasoning (an example from math education literature [75]). The integrated model we propose is also more consistent with the emerging evidence from psychology and neuroscience $[2,4,63]$. Second, as we discuss in the section after next, such an integrative account has implications for instructional strategies and design of measurement instruments in education that differ significantly from the implications borne out of a cold cognitive account. Even attention to emotions, without entangling them in the conceptual and epistemological dynamics will lead to very different conclusions, both for conceptual and epistemological learning and for emotional well-being in the classroom. If we take these divergent implications seriously, that could afford the collection of new data based on new instructional interventions, perhaps making possible the empirical teasing apart of the hot and cold cognition accounts. Third, from a values perspective, we think that what we lose on the Occam's razor is worth losing if we can elevate an account that forefronts the complexities of the emotional life of the learner.

However, there might be a number of counterarguments to the account itself and we address those next.

\section{B. Counterinterpretations to our hot cognitive account}

A counterargument could be that our analysis does not attend closely to the interactions between Judy and Brian and that epistemologies and emotions we attribute to Judy are, in fact, properties of the interaction. We do think that Brian's and Judy's interactions play some role in constructing the particular form and, to some extent, the content of Judy's utterances. For example, when Brian asks about the ideal version of the course for the hypothetical professional engineer, the question itself presupposes that something in the course potentially needs fixing. It also focuses attention on the professional needs of an electrical engineer beyond the immediate course-relevant needs of an undergraduate student embedded in a particular program. This could have positioned the course in the broader real world context, prompting Judy to attend to differences between that the idealized models discussed in the course and real life circuits. However, Brian's prompts did not determine the specific ways in which Judy contrasts real circuits and idealized models. Given these prompts, other students could acknowledge the real-ideal distinction but argue for the value in reasoning with idealized models, even for future real world applications. And indeed, in a different paper, we document another student from the same course who argues that building deep conceptual reasoning is what is most valuable for future professional work [76].

Furthermore, although Brian cued Judy to consider the different kinds of homework problems assigned in the course, Judy's statement that the "physical questions" are annoying was spontaneous. Our analysis of Judy's reactions there support the idea that the distinction between regular problems and those that asked to reason with idealized models was something that Judy had noticed before. In short, we think that the interaction influenced the structure and sequence of Judy's utterances; however, we think that some of the content of those utterances can be attributed to Judy, at least locally, and with the caveat that the stability of the stances espoused in the utterances is jointly achieved in the interview, not a "cognitive fact" about Judy.

One could argue that while we are modeling the emotionepistemology-conception connections, we are not modeling the equally important instructional environment within which those connections are embedded. We agree that the instructional environment plays a crucial role in generating and sustaining the phenomena we observe. For example, we see glimmers of this when Judy reflects on her perception that the course provides limited support for helping students (not just her) answer the "physical" questions. Homework in the course was graded partly for correctness and good grades 
matter when engineering graduates apply for jobs. Furthermore, institutional structures likely shape expectations for how courses are connected to students' future trajectories within and outside the academy. So, the hot cognitive story we constructed is inherently incomplete in not modeling these contextual and sociocultural aspects in detail. We do not have extensive data to flesh out this more sociocultural story, but we do not think the account we created, though incomplete, would conflict with it.

Another paradigm-based critique of our analysis is as follows: From a situativist view, learning is inherently tied with becoming more central participants within communities of practice, not simply the cognitive acquisition of knowledge and skills. From this perspective, our account is based too much in Judy's head - her personal epistemologies and her emotions. While we err on the cognitivist side, we do note that part of our story is Judy's perception of her own future trajectories: imagining the course's value to a professional engineer brings up the gulf between real circuits and idealized models and the limited utility of idealized models. We agree that access to how Judy is gradually coming to participate more centrally in the electrical engineering community, and how those experiences shape the epistemological stances and emotions that we observe, will provide a richer and more complete account. The current data, which lack in situ observations of Judy interacting with other students, professors, and engineers (e.g., in summer internships), prevent us from telling a situativist story. This is a limitation of the study. However, our limited account, in drawing attention to the fine-timescale entanglement of emotions with epistemologies and conceptions, still makes a contribution to our understanding of how people learn. Introducing emotions into our account does not make it complete but makes it more complete—or at least different from-cold cognitive accounts.

Another critique might be that we are treating emotions as an internal psychological phenomenon ("Judy's annoyance") while emotions are produced in interaction and can be interpreted only within the interaction systems in which they are produced [77]. We reject a sense of dichotomy between emotions as psychological versus interactional; we think it is both. In our argument, Judy's sense of annoyance connects explicitly to her experience in the course and plausibly to her broader academic experience. The local interactional environment allows for the expression and interpretation of particular emotions which in turn play their role in constituting the local interactional environment. The emotions in play during the interview help establish meaning between the interviewee and interviewer. In this sense, the emotions "live" in the interaction. But at the same time, Judy's physiological reactions also provide evidence that she is feeling particular emotions. These accounts are not in tension for us; we can imagine Judy having particular physiological reactions that are reflexively coupled with the local interview situation and the broader academic context. For the purpose of understanding how learners' epistemologies and conceptions are coupled with their emotions (a cognitivist framing of the issue that we inherit from the history of work on conceptions and epistemologies), we adopt the psychological account of emotions, attributing them to Judy and modeling the local situation and broader academic context as constraints that generate or sustain the emotion-epistemologyconception coupling. Of course, this prevents us from modeling the situation from a fully interactional or sociocultural perspective, which is a limitation.

\section{Implications}

Beyond these counterinterpretations, there is also the issue of generalization: Can we make inferences from the case study of a single student reflecting on her course experiences and solving problems over a single interview? Our answer to this is a firm, "yes, though with caution." To be clear, we are not claiming that all or most students in the course experienced similar emotions and epistemological stances, and hence it would be a mistake to recommend instructional "improvements" based on that. However, as Yin [64] and others argue, a single case study can be "revelatory" for drawing attention to particular overlooked phenomenon and for suggesting causal links that likely exist in other cases though they likely play out differently. Here, the overlooked (or at least underexplored) phenomenon is co-occurring stabilities and shifts in emotions and epistemological stances.

Single case studies can also serve as existence proofs [64]. We view the Judy case study as an existence proof of (i) the methodological tractability of bringing emotions into fine-grained analysis of epistemologies and conceptions, and (ii) the idea that such an account can be a plausible alternative to a cold cognitive account.

Still, Brian's interviews with other students in the circuits course suggest that Judy's reactions to the conceptual problems are not atypical, making it worthwhile to think about what tentative implications can be drawn from this case study, with the caution that any implications would need further investigation and refinement.

The first implication speaks to PER's strong emphasis on instructional interventions that focus on conceptual development across topics ranging from Newtonian mechanics to electromagnetism to quantum mechanics. This research has led to successful curricula and instructional strategies. However, less work has been done to inform the design of holistic, structural course improvements to support students' conceptual sense making. For example, how should instructors organize office hours and study groups to help students achieve success on conceptual questions? More important, most research and development on conceptual learning has focused on helping students learn discrete concepts in a course; and much of this work has taken place in physics courses for life science and engineering majors. In these courses, students like Judy might question the utility of 
conceptual knowledge towards their future professional goals. To help these students buy into research-based instructional practices, we need to address how their trajectory within the course aligns with their longer professional journey. Preliminary evidence suggests that this shift in perspective can lead to radical changes in how we design courses [78], and that anticipating, attending and responding to students' unsettled and/or negative emotions is an essential design element [54]. Further studies of students' entangled emotions and conceptual reasoning could inform this design work.

Within physics education research, another prominent line of work has addressed students' epistemologies $[61,79,80]$. This work has documented that students often see a discontinuity between their intuitive or everyday knowledge and formal physics knowledge. This perceived "wall" between different pools of knowledge is similar to Judy's sharp distinction between formal knowledge about real circuits and knowledge about idealized models. Both the real or ideal and the formal or everyday distinctions hint at a divide between the world of the physics or engineering classroom and the world outside. Some instructional interventions specifically aim at helping students draw on their everyday knowledge in physics classrooms $[81,82]$. That students do not automatically draw upon their everyday knowledge in formal learning environments is often seen as an epistemological deficit they have acquired through participation in earlier physics or science classes $[29,31,33,36,83]$. Instructional interventions, measurement instruments (e.g., CLASS and MPEX), and cognitive models have been limited to viewing this "deficit" as a cold cognitive phenomenon arising from students' epistemologies and their expectations about a course. Judy's case shows us that, instead of viewing learners' sense of this divide between formal and everyday knowledge as a deficit, we should aim to understand it as deeply entangled with their emotions and their disciplinary identities and future trajectories as well as reinforced through the structure and resources of the course and institutional context. This shift in our view as researchers and instructors could lead to new instructional insights that take into account the whole learner and not just their conceptual and epistemological states.

In summary, PER has focused heavily on learners' cold cognitive conceptual and epistemological development, and productively so: this has led to significant insights into modeling learning and learners and into creating change in classrooms. However, Judy's case study hints that, we as researchers (though not we as people and teachers) might have neglected to view the learner as a person with emotions, wanting to succeed, and with a view toward their future professional selves. Given the leaps that PER has made in improving physics instruction by attending closely to students' conceptions and epistemologies, now it is time to attend to how the emotional lives of learners interact in the moment with those conceptions and epistemologies.

\section{ACKNOWLEDGMENTS}

We thank "Judy" for her participation in the study. We thank the instructor of the circuits course for allowing us access to students, sharing course materials, and incorporating suggested modifications into the curriculum. We thank Chandra Turpen for help generating initial versions of the visual representations of our model. We thank Eric Kuo, Michael Hull, David Hammer, and members of the Physics Education Research Group at the University of Maryland for productive discussions around this data at various group meetings. We thank Jim Pellegrino and Ann R. Edwards for feedback on this work at an advisory board meeting. A. G.'s thoughts on the role of emotions in learning have also been significantly influenced through extensive discussions with Luke Conlin, Lama Jaber, Jennifer Radoff, Jennifer Richards, Vashti Sawtelle, Chandra Turpen, and Jessica Watkins. We also thank Ricardo Nemirovsky for encouragement in continuing this line of work, based on earlier versions of the argument in this manuscript. This work was supported in part by NSF EEC-0835880 and NSF DRL-0733613. The opinions in this article are of the authors only.

\section{APPENDIX A: SAMPLE ASSIGNMENT QUESTIONS FROM CIRCUITS COURSE}

In this section we provide three sample problems from the class assignments in the circuits course. The assignments were initially designed by the course instructor and then slightly modified by Gupta and Elby.

\section{Sample Problem 1}

If a square wave, a triangle wave, and a sine wave all have the same RMS voltage, which wave has the largest peak voltage and which has the smallest peak voltage?

(a) Without computing the expressions for the peak voltages, reason about which of the three voltage waves should have smallest peak voltage?

(b) Prove your answer quantitatively.

(c) Interpret the integral equation used in part (b). In other words, what does the integral in the expression for RMS voltage physically represent?

\section{Sample Problem 2}

John "explains" to Jasmine, after the battery in his calculator died, that a $9 \mathrm{~V}$ battery can be used to charge a $1.5 \mathrm{~V}$ battery simply by connecting their negative terminals together and connecting a large resistor between their positive terminals. Jasmine said that her friend Sven said that you need more than one resistor. (Circuit is shown in Fig. 9).

(a) Who is right, John or Sven? Why?

(b) Given the presence of the other two resistors, what role does $R$ play in the circuit? In other words, why is it there?

(c) What value should Sven use for $R$ ? Explain your reasoning. 


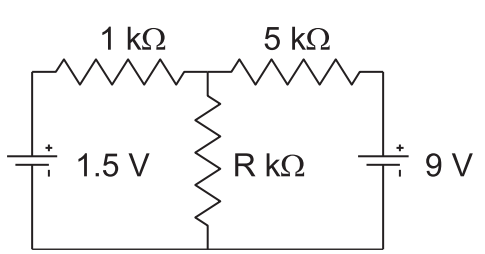

FIG. 9. Circuit for sample problem 2.

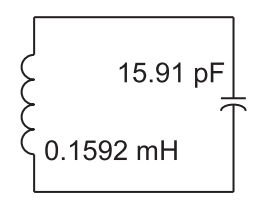

FIG. 10. Circuit for sample problem 3.

\section{Sample Problem 3}

One day Sven and his cousin Ana, who works for $S C E$, stop by to see Jasmine, and John is at the apartment struggling with a Basic Electric Circuit problem. Sven, an ECE major who actually attends classes, tries to see if he can help John (not by giving him the answer, but by helping him understand the concepts necessary to do the problem). All that Sven says to John is "What are the possible terminals that you could use to find the input impedance?" What are the correct answers to the problem below?

The problem goes like this:

(a) Assume you have the problem shown in the Fig. 10. Are these components in series or parallel. Explain your reasoning.

(b) Now think why someone else could have answered differently for (a). What could have been their reasoning. How would you respond to them?

(c) Calculate the frequency at which the input impedance of this circuit is infinity.

(d) Rearrange the components so that the input impedance is zero at the same frequency.

(e) Explain (in words) what is happening in the circuit that yields such diverse impedances with a simple change in geometry. In other words, explain if your results make sense just by reasoning in terms of what is physically happening in the circuit.

\section{APPENDIX B: LIST OF POTENTIAL QUESTIONS AVAILABLE TO THE INTERVIEWER FOR THE INTERVIEW}

In this section we provide the interview prompts available to the interviewer, Brian, at the time of the interview. Note that the prompts were not meant to be prescriptive, but rather meant to support Brian in having a meaningful conversation with the interviewee, Judy.

1. How is the course going for you? Is there any issue about the course you'd like to talk about?

Follow-up: pursue epistemological angle.
2. What would happen in an ideal discussion section for this course?

3. What aspects of this course do you think are helpful to you as a future professional engineer?

4. Imagine a professional engineer, "Diana," whose new work assignment has her doing more stuff with circuits than she did in the past. She's taking this course to bone up, and she's not getting graded. For Diana what would an ideal discussion section be like?

Follow-ups: Focus on similarities and differences between Diana vs student's ideal.

5. A student whose opinion I heard earlier noticed that the homework and tests contain two kinds of questions: Quantitative ones where the answer is mathematical, and qualitative, conceptual ones where the answer is words. What do you think of the two kinds of questions. [Have an example ready to illustrate the difference, if needed]

6. Is one kind of question more helpful than the other for you?

7. Do you think Diana would have the same viewpoint?

8. How do you know when you really understand an equation?

9. Think about the following circuit (shown in Fig. 11). The voltage potential at any point along that wire with resistance of $\rho$ per $\mathrm{cm}$ is given as $V=V_{0}-\rho I l, I$ is the current through the wire and $l$ is the length from the battery end to the position at which voltage potential is measured.

How would you explain that equation to a friend from class?

If just a formal answer, then follow up with: How would you explain that equation to a 10th grader?

If just conceptual reasoning, then follow with: How would you explain that equation on an exam

10. Consider the following circuit in Fig. 12. The voltage across $R_{2}$ is given as $V_{2}=V-I R_{1}$, where $I$ is the current in the circuit. How would you explain that equation to a friend from class?

[Same pattern of follow up questions]

11. Then, how would you solve for the current in the circuit shown in Fig. 13 after the switch is closed.

At this stage, students might try a variety of things: and it might be good to press on how they put meaning to the math that they do. This also offers opportunities to probe their sense of what is integration and differentiation.

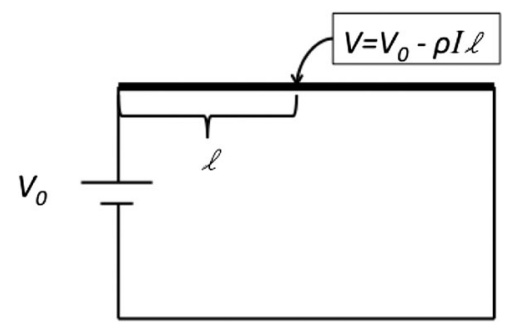

FIG. 11. Circuit for Appendix B, item 9. 


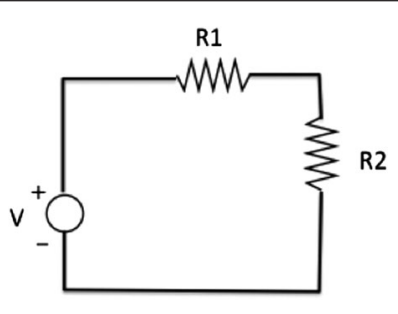

FIG. 12. Circuit for Appendix B, item 10.

12. This was one of your HW questions in the course. Just work through it, speaking aloud what you are thinking. Don't worry about the right answer, I just want to see how you approach the problem.

If a square wave, a triangle wave, and a sine wave all have the same RMS voltage, which wave has the largest peak voltage and which has the smallest peak voltage?

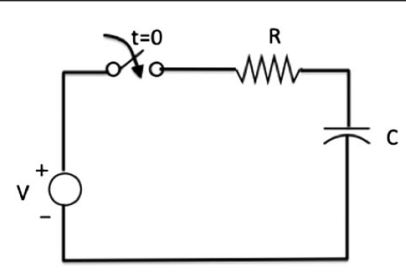

FIG. 13. Circuit for Appendix B, item 11.

(a) Without computing anything, figure out which of the three waves has the largest and smallest peak voltage? Explain your reasoning.

(b) Prove your answer quantitatively.

(c) Interpret the integral equation used in part (b). In other words, what does the integral in the expression for RMS voltage mean, physically?

Probe their understanding of the integration expression for $V_{\mathrm{RMS}}$
[1] G. H. Bower, How might emotions affect learning, in The Handbook of Emotion and Memory: Research and Theory 3 (Lawrence Earlbaum Associates, Inc., Mahwah, NJ, 1992).

[2] A. Damasio, Descartes' error: Emotion, reason, and the human brain, in Descartes' Error: Emotion, Reason, and the Human Brain (Penguin (Non-Classics), New York, 2005).

[3] W. C. Drevets and M. E. Raichle, Suppression of regional cerebral blood during emotional versus higher cognitive implications for interactions between emotion and cognition, Cognition and emotion 12, 353 (1998).

[4] J. P. Forgas, Mood and judgment: The affect infusion model (AIM), Psychol. Bull. 117, 39 (1995).

[5] D. A. Norman, Twelve issues for cognitive science, Cogn. Sci. 4, 1 (1980).

[6] C. M. Steele, A threat in the air: How stereotypes shape intellectual identity and performance, Am. Psychol. 52, 613 (1997).

[7] B. Weiner, An attributional theory of achievement motivation and emotion, Psychol. Rev. 92, 548 (1985).

[8] D. B. McLeod and V. M. Adams, Affect and mathematical problem solving: A new perspective, Affect and Mathematical Problem Solving: A New Perspective (Springer Verlag, New York, 1989).

[9] P. R. Pintrich, R. W. Marx, and R. A. Boyle, Beyond cold conceptual change: The role of motivational beliefs and classroom contextual factors in the process of conceptual change, Rev. Educ. Res. 63, 167 (1993).

[10] E. A. Silver, L. J. Shapiro, and A. Deutsch, Sense making and the solution of division problems involving remainders: An examination of middle school students' solution processes and their interpretations of solutions, J. Res. Math. Educ. 24, 117 (1993).
[11] R. Zan, L. Brown, J. Evans, and M. S. Hannula, Affect in mathematics education: An introduction, Educ. Stud. Math. 63, 113 (2006).

[12] G. J. Posner, K. A. Strike, P. W. Hewson, and W. A. Gertzog, Accommodation of a scientific conception: Toward a theory of conceptual change, Sci. Educ. 66, 211 (1982).

[13] S. Carey, Cognitive science and science education, Am. Psychol. 41, 1123 (1986).

[14] M. T. H. Chi, J. D. Slotta, and N. De Leeuw, From things to processes: A theory of conceptual change for learning science concepts, Learn. Instr. 4, 27 (1994).

[15] A. A. diSessa and B. L. Sherin, What changes in conceptual change?, Int. J. Sci. Educ. 20, 1155 (1998).

[16] A. A. diSessa, Toward an epistemology of physics, Cognit. Instr. 10, 105 (1993).

[17] B. L. Sherin, How students understand physics equations, Cognit. Instr. 19, 479 (2001).

[18] S. Vosniadou, Capturing and modeling the process of conceptual change, Learn. Instr. 4, 45 (1994).

[19] D. Hammer, Student resources for learning introductory physics, Am. J. Phys. 68, S52 (2000).

[20] M. McCloskey, Naive theories of motion, in Mental Models, edited by D. Gentner and A. L. Stevens (Erlbaum, Hillsdale, NJ, 1983), p. 299.

[21] L. C. McDermott et al., Millikan Lecture 1990: What we teach and what is learned-Closing the gap, Am. J. Phys. 59, 301 (1991).

[22] L. C. McDermott and P. Schaffer, Research as a guide for curriculum development: An example from introductory electricity. Part I: Investigation of student understanding, Am. J. Phys. 60, 994 (1992). 
[23] L. C. McDermott, Oersted medal lecture 2001: "Physics Education Research - the key to student learning", Am. J. Phys. 69, 1127 (2001).

[24] E. F. Redish, Millikan Lecture 1998: Building a science of teaching physics, Am. J. Phys. 67, 562 (1999).

[25] F. Reif, Millikan Lecture 1994: Understanding and teaching important scientific thought processes, Am. J. Phys. 63, 17 (1995).

[26] L. Hsu, E. Brewe, T. M. Foster, and K. A. Harper, Resource Letter RPS-1: Research in problem solving, Am. J. Phys. 72, 1147 (2004).

[27] L. C. McDermott and E. F. Redish, Resource Letter: PER1: Physics education research, Am. J. Phys. 67, 755 (1999).

[28] B. K. Hofer and P. R. Pintrich, The development of epistemological theories: Beliefs about knowledge and knowing and their relation to learning, Rev. Educ. Res. 67, 88 (1997).

[29] T. J. Bing and E.F. Redish, Analyzing problem solving using math in physics: Epistemological framing via warrants, Phys. Rev. ST Phys. Educ. Res. 5, 020108 (2009).

[30] M. Bodin and M. Winberg, Role of beliefs and emotions in numerical problem solving in university physics education, Phys. Rev. ST Phys. Educ. Res. 8, 010108 (2012).

[31] A. Gupta and A. Elby, Beyond epistemological deficits: Dynamic explanations of engineering students' difficulties with mathematical sense-making, Int. J. Sci. Educ. 33, 2463 (2011).

[32] D. Hammer, A. Elby, R. E. Scherr, and E. F. Redish, Resources, framing, and transfer, in Transfer of Learning from a Modern Multidisciplinary Perspective, edited by J. P. Mestre (IAP, Greenwich, CT, 2005), p. 89.

[33] L. Lising and A. Elby, The impact of epistemology on learning: A case study from introductory physics, Am. J. Phys. 73, 372 (2005).

[34] L. Louca, A. Elby, D. Hammer, and T. Kagey, Epistemological resources: Applying a new epistemological framework to science instruction, Educ. Psychol. 39, 57 (2004).

[35] S. Rosenberg, D. Hammer, and J. Phelan, Multiple epistemological coherences in an eighth-grade discussion of the rock cycle, J. Learn. Sci. 15, 261 (2006).

[36] J. Tuminaro and E. F. Redish, Elements of a cognitive model of physics problem solving: Epistemic games, Phys. Rev. ST Phys. Educ. Res. 3, 020101 (2007).

[37] L. F. Barrett, B. Mesquita, K. N. Ochsner, and J. J. Gross, The experience of emotion, Annu. Rev. Psychol. 58, 373 (2007).

[38] S. Duncan and L. F. Barrett, Affect is a form of cognition: A neurobiological analysis, PCEM 21, 1184 (2007).

[39] F. C. Bartlett and C. Burt, Remembering: A study in experimental and social psychology, Br. J. Educ. Psychol. 3, 187 (1933).

[40] L. F. Barrett, Discrete emotions or dimensions? The role of valence focus and arousal focus, Cognition and emotion 12, 579 (1998).

[41] R. Duit and D. F. Treagust, Conceptual change: A powerful framework for improving science teaching and learning, Int. J. Sci. Educ. 25, 671 (2003).
[42] L. M. Tyson, G. J. Venville, A. G. Harrison, and D. F. Treagust, A multidimensional framework for interpreting conceptual change events in the classroom, Sci. Educ. 81, 387 (1997).

[43] M. Gregoire, Is it a challenge or a threat? A dual-process model of teachers' cognition and appraisal processes during conceptual change, Educ. Psychol. Rev. 15, 147 (2003).

[44] R. Pekrun, T. Goetz, W. Titz, and R. P. Perry, Academic emotions in students' self-regulated learning and achievement: A program of qualitative and quantitative research, Educ. Psychol. 37, 91 (2002).

[45] S. D. Craig, A. C. Graesser, J. Sullins, and B. Gholson, Affect and learning: An exploratory look into the role of affect in learning with AutoTutor, Journal of educational media and library sciences 29, 241 (2004).

[46] S. D'Mello, R. W. Picard, and A. Graesser, Toward an affect-sensitive AutoTutor, IEEE Intelligent Systems 22, 53 (2007).

[47] J. Boaler and J. Greeno, Identity, agency and knowing in mathematics worlds, in Multiple Perspectives on Mathematics Teaching and Learning, edited by J. Boaler (Ablex Publishing, Westport, CT, 2000), pp. 171-200.

[48] P. Cobb, E. Yackel, and T. Wood, Young children's emotional acts while engaged in mathematical problem solving, in Affect and Mathematical Problem Solving, edited by D. B. McLeod and V. M. Adams (Springer, New York, 1989), p. 117.

[49] V. A. DeBellis and G. A. Goldin, Affect and meta-affect in mathematical problem solving: A representational perspective, Educ. Studies Math. 63, 131 (2006).

[50] P. Eynde, E. Corte, and L. Verschaffel, "Accepting emotional complexity": A socio-constructivist perspective on the role of emotions in the mathematics classroom, Educ. Studies Math. 63, 193 (2006).

[51] C. Kim, S. W. Park, and J. Cozart, Affective and motivational factors of learning in online mathematics courses, $\mathrm{Br}$. J. Educ. Technol. 45, 171 (2014).

[52] K. Weber, The role of affect in learning real analysis: A case study, Res. Math. Educ. 10, 71 (2008).

[53] M. Zembylas, Young children's emotional practices while engaged in long-term science investigation, J. Res. Sci. Teach. 41, 693 (2004).

[54] L.Z. Jaber and D. Hammer, Learning to feel like a scientist, Sci. Educ. 100, 189 (2016).

[55] S. Alsop and M. Watts, Facts and feelings: Exploring the affective domain in the learning of physics, Phys. Educ. 35, 132 (2000).

[56] D. B. Clark, C. M. D’Angelo, and S. P. Schleigh, Comparison of students' knowledge structure coherence and understanding of force in the Philippines, Turkey, China, Mexico, and the United States, J. Learn. Sci. 20, 207 (2011).

[57] D. B. Clark, Longitudinal conceptual change in students' understanding of thermal equilibrium: An examination of the process of conceptual restructuring, Cognit. Instr. 24, 467 (2006).

[58] O. Parnafes, What does fast mean? Understanding the physical world through computational representations, J. Learn. Sci. 16, 415 (2007). 
[59] B. L. Sherin, M. Krakowski, and V. R. Lee, Some assembly required: How scientific explanations are constructed during clinical interviews, J. Res. Sci. Teach. 49, 166 (2012).

[60] D. Stamovlasis, G. Papageorgiou, and G. Tsitsipis, The coherent versus fragmented knowledge hypotheses for the structure of matter: an investigation with a robust statistical methodology, Chem. Educ. Res. Pract. 14, 485 (2013).

[61] D. Hammer and A. Elby, On the form of a personal epistemology, in Personal Epistemology: The Psychology of Beliefs about Knowledge and Knowing, edited by B. K. Hofer and P. R. Pintrich (L. Erlbaum Associates, Mahwah, N.J, 2002), p. 169.

[62] P. B. Carr and C. M. Steele, Stereotype threat and inflexible perseverance in problem solving, J. Exp. Soc. Psychol. 45, 853 (2009).

[63] J. E. LeDoux, Emotion circuits in the brain, Annu. Rev. Neurosci. 23, 155 (2000).

[64] R. K. Yin, Case study research: Design and methods, Case Study Research: Design and Methods (Sage, Newbury Park, CA, 2009).

[65] S. J. Derry, R. D. Pea, B. Barron, R. A. Engle, F. Erickson, R. Goldman, R. Hall, T. Koschmann, J. L. Lemke, and M. G. Sherin, Conducting video research in the learning sciences: Guidance on selection, analysis, technology, and ethics, J. Learn. Sci. 19, 3 (2010).

[66] R. E. Scherr, Video analysis for insight and coding: Examples from tutorials in introductory physics, Phys. Rev. ST Phys. Educ. Res. 5, 020106 (2009).

[67] A. H. Schoenfeld, On paradigms and methods: What do you do when the ones you know don't do what you want them to? Issues in the analysis of data in the form of videotapes, J. Learn. Sci. 2, 179 (1992).

[68] R. S. Siegler and K. Crowley, The microgenetic method: A direct means for studying cognitive development, Am. Psychol. 46, 606 (1991).

[69] T. Stivers and J. Sidnell, Introduction: Multimodal interaction, Semiotica 156, 1 (2005).

[70] A. A. diSessa, What do "just plain folk" know about physics, in The Handbook of Education and Human Development: New Models of Learning, Teaching, and Schooling (Wiley-Blackwell, Hoboken, NJ, 1996), pp. 709-730.
[71] A. Gupta, B. A. Danielak, and A. Elby, Understanding students' difficulties in terms of coupled epistemological and affective dynamics, in Proceedings of the 40th Annual Frontiers in Education Conference-Celebrating 40 Years of Innovation, Washington, DC (IEEE, Piscataway, NJ, 2010).

[72] J. Gainsburg, The mathematical modeling of structural engineers, Math. Thinking Learning 8, 3 (2006).

[73] M. Cole, Cultural psychology: A once and future discipline, Cultural Psychology: A Once and Future Discipline (Harvard University Press, Cambridge, MA, 1998).

[74] K. A. Strike and G. J. Posner, A revisionist theory of conceptual change, in Philosophy of Science, Cognitive Psychology, and Educational Theory and Practice, edited by R. A. Duschl and R. J. Hamilton (State University of New York Press, Albany, NY, 1992), Vol. 176, pp. 147176.

[75] I. Esmonde, Explanations in mathematics classrooms: A discourse analysis, Canadian J. Sci. Math. Technol. Educ. 9, 86 (2009).

[76] B. A. Danielak, A. Gupta, and A. Elby, Marginalized identities of sense-makers: Reframing engineering student retention, J. Eng. Educ. 103, 8 (2014).

[77] M. Zembylas, Three perspectives on linking the cognitive and the emotional in science learning: Conceptual change, socio-constructivism and poststructuralism, Studies Sci. Educ. 41, 91 (2005).

[78] V. Sawtelle and C. Turpen, Leveraging a relationship with biology to expand a relationship with physics, Phys. Rev. Phys. Educ. Res. 12, 010136 (2016).

[79] W. K. Adams, K. K. Perkins, N. S. Podolefsky, M. Dubson, N. D. Finkelstein, and C. E. Wieman, New instrument for measuring student beliefs about physics and learning physics: The Colorado Learning Attitudes about Science Survey, Phys. Rev. ST Phys. Educ. Res. 2, 010101 (2006).

[80] E. F. Redish, J. M. Saul, and R. N. Steinberg, Student expectations in introductory physics, Am. J. Phys. 66, 212 (1998).

[81] A. Elby, Helping physics students learn how to learn, Am. J. Phys. 69, S54 (2001).

[82] E. F. Redish and D. Hammer, Reinventing college physics for biologists: Explicating an epistemological curriculum, Am. J. Phys. 77, 629 (2009).

[83] D. Hammer, Epistemological beliefs in introductory physics, Cognit. Instr. 12, 151 (1994). 